Revista de Comunicación y Salud, 2021, Vol. 11, 19-57

Editado por Cátedra de Comunicación y Salud

ISSN: 2173-1675

\title{
MARKETING DE INFLUENCIA: EDUCACIÓN SANITARIA ONLINE
}

Influencer marketing: online health education

\author{
Ainhoa García Rivero ${ }^{1}$ \\ Universidad Complutense de Madrid. España. \\ ainhoa02@ucm.es \\ Emma G. Carbonell-Curralo \\ Universidad Complutense de Madrid. España. \\ emmacarb@ucm.es \\ Ana Magán-Álvarez \\ Universidad Complutense de Madrid. España. \\ anamagan@ucm.es \\ Rafael Barberá-González \\ Universidad Complutense de Madrid. España. \\ rbarbera@ucm.es
}

\section{Cómo citar el artículo}

García Rivero, A., Carbonell-Curralo, E. G., Magán-Álvarez, A. y Barberá-González, R. (2021). Marketing de influencia: educación sanitaria online. Revista de Comunicación y Salud, 11, 19-57. https://doi.org/10.35669/rcys.2021.11.e268

\section{Resumen}

Internet y las redes sociales han supuesto un antes y un después en el intercambio de información sanitaria. Este proceso ha generado consecuencias como la pérdida de control sobre la información disponible, así como el riesgo de educar en salud de una manera errónea. En el presente estado de la cuestión se aborda, entre otros temas, el

${ }^{1}$ Autor principal: Ainhoa García Rivero. Universidad Complutense de Madrid. ainhoa02@ucm.es 
marketing de influencia en la promoción de productos y servicios relacionados con el ámbito de la salud para, a continuación, ofrecer una perspectiva actual de los procesos comunicativos entre la ciudadanía y las figuras influyentes del panorama online. Gracias a una encuesta online, se han podido identificar varios influencers que compartían en Instagram alguna recomendación sobre productos de salud. Con esta muestra, se han analizado diferentes publicaciones y se han obtenido diversas conclusiones. Algunos de los resultados obtenidos en el análisis de estos perfiles es que los influencers obtienen más reconocimiento y repercusión que los perfiles de profesionales y expertos sanitarios. Además, los posts que versan sobre productos relacionados con la salud obtienen grandes datos de engagement a pesar de ser contenido comercial, lo que significa una buena aceptación por parte del público. La clave del éxito de las campañas de marketing de influencia en el sector de la salud reside en la enorme confianza que depositan los seguidores sobre los influencers, lo que supone un verdadero riesgo, pues en la mayoría de los casos no se trata de información veraz y de calidad.

Palabras Clave: Educación sanitaria; Redes sociales; Estrategias de e-salud; Marketing de influencia; Salud electrónica; Instagram.

\begin{abstract}
Internet and social networks represent a turning point in healthcare information exchange. This process has generated consequences such as the loss of control over the information available, or the risk of health education in a wrong way. The state of the question addresses the marketing of influence on health-related products and services. Consequently, this article aims to offer a present-day perspective about the communication processes between citizens and influential characters from the online scene. Thanks to an online survey, plenty of influencers that shared any recommendation of health products have been identified. Thanks to this sign, different publications have been analysed and several conclusions have been obtained. Some of the obtained results in the analysis of these profiles is that influencers gain more recognition and repercussion rather than proffesional profiles and sanitary experts. In addition, the posts that are related to sanitary products achieve an enormous quantity of engagement datum despite being comercial content, which means a good public acceptation. The key to success in marketing campaigns of influence in the health sector is the gigantic trust that the followers have on influencers, which means a big risk because, most of the times, it is not a good source of trustful information.
\end{abstract}

Keywords: Health Education; Social Networking; e-Health Strategies; Influencer Marketing; Online Health; Instagram.

\title{
1. INTRODUCCIÓN
}

La presente revisión bibliográfica versa sobre los efectos que ha supuesto el empleo de Internet, tanto para la generación de conversaciones online en torno al ámbito sanitario, como para fomentar la compra de artículos dirigidos a la promoción de la salud. 
Las plataformas que han ido generándose en Internet a lo largo del tiempo, han aportado distintos beneficios según las prácticas que éstas permitiesen desarrollar. Cabe destacar, por un lado, el empoderamiento del paciente a la hora de encarnar un papel más activo e informarse sobre aspectos relacionados con su salud y, por otro, la posibilidad de desarrollar interacciones más rápidas e inmediatas entre los profesionales sanitarios y la ciudadanía.

El asentamiento de las aplicaciones móviles o las redes sociales trae consigo la aparición de prescriptores de gran repercusión que fomentan hábitos en sus seguidores, ya sea en su consumo o en sus costumbres. Ante esta coyuntura, las marcas han recurrido al marketing de influencia como herramienta de comunicación, logrando un mayor alcance utilizando a los influencers como intermediarios entre su producto y su público objetivo.

Este panorama supone un nuevo reto para la comunicación en salud, donde entran en juego factores como la calidad de la información proporcionada por usuarios que, a pesar de tener gran influjo social, no son expertos en los temas que abordan. En consecuencia, resulta fundamental el papel que juegan en este contexto los profesionales sanitarios ya que ellos sí que tienen la capacidad de promover una comunicación que favorezca la alfabetización sanitaria de la ciudadanía, al contrario que los influencers no especializados.

A pesar de lo fundamental que resulta la colaboración conjunta entre las instituciones, las empresas, los organismos educativos y los profesionales sanitarios, en este artículo se muestran una serie de casos, obtenidos de Instagram, con los que se ejemplifican situaciones en las que se promueve la comunicación para el desarrollo, así como en las que se fomenta la comunicación comercial en el ámbito de la salud.

\section{OBJETIVOS}

Los objetivos concretos que se plantean en esta revisión bibliográfica son:

1. Averiguar las relaciones existentes entre Internet y el ámbito sanitario.

2. Conocer el vínculo entre el marketing de influencia y el sector de la salud.

3. Identificar la influencia de las redes sociales sobre la educación en salud de los ciudadanos.

Como objetivos secundarios de este tercer objetivo, nos encontramos con:

1. Determinar si los influencers no profesionales tienen más o menos capacidad de influencia que los influencers expertos en materia de salud.

2. Conocer cómo son los posts de productos vinculados con la salud publicados por los influencers en Instagram.

\section{METODOLOGÍA}


Para llevar a cabo esta investigación se han planteado una serie de objetivos, anteriormente citados, y se ha consultado en los Descriptores en Ciencias de la Salud para localizar los términos con los que iniciar la investigación y, consecuentemente, afrontar la búsqueda de información relativa al objeto de estudio.

A continuación, se ha procedido a realizar una revisión de la literatura para detectar y recuperar materiales útiles con los que abordar el presente artículo. Las fuentes de investigación a las que se ha acudido son, en su mayoría, fuentes primarias, siendo gran pate de ellas artículos científicos. Así mismo, tras definir el contexto, se ha procedido a la identificación y análisis de una serie de ejemplos, en el ámbito español, con los que ilustrar el problema abordado y el discurso del artículo.

El motivo por el que se ha seleccionado Instagram como la plataforma de análisis guarda relación con los datos aportados en el último Estudio Anual de Redes publicado por IAB Spain (2020). En base a este documento, puede afirmarse que Instagram es una red social generada para el entretenimiento, siendo este el objetivo por el que el $81 \%$ de la población española utiliza redes sociales. Además, ofrece alta notoriedad entre las organizaciones a nivel comercial y es la red social donde más se sigue a los influencers.

Para ofrecer algunos ejemplos de los procesos comunicativos entre la ciudadanía y las figuras influyentes del panorama online se ha elegido una muestra compuesta por personajes que destacan en Instagram, que recojan en sus publicaciones contenidos relacionados con el tema a investigar y que tengan reconocimiento público en España. A la hora de seleccionar a estos personajes públicos se ha tenido en cuenta el número de seguidores a partir de la clasificación propuesta por IAB España (2019), que considera influencer a aquella persona que detenta entre 250.000 y un millón de seguidores, y top influencer a la que tiene más de un millón de seguidores.

De este modo, a partir de una encuesta online se ha procedido a analizar siete influencers y a tres top influencers con reconocimiento por parte del público no fan. Este sondeo nos ha permitido saber qué influencers recuerda la gente en primer lugar cuando se les pregunta por publicaciones de productos vinculados con la salud. Con esta información, se ha procedido a analizar sus perfiles y a extraer ejemplos de ellos que pudiesen ejemplificar el discurso del presente trabajo.

Analizando la naturaleza de la muestra, se observan seis influencers de naturaleza no nativa (aquellos que eran famosos antes de tener éxito en las redes sociales) y otros cuatro de naturaleza nativa. Según IAB (2019), los influencers nativos son aquellos que han conseguido seguidores "como consecuencia de los actos que muestra en RRSS, lugar en el que se dio a conocer por primera vez" (p. 7). Sin embargo, los influencers no nativos son conocidos por su trabajo en otros medios y que ha conseguido trasladar ese reconocimiento a sus perfiles de redes sociales, como los deportistas, cantantes, etc.

Así, se procede a señalar ejemplos en los que estas personalidades difunden contenido con un objetivo publicitario. Para ello se tendrán en cuenta cuatro variables: tipo de publicidad (implícita o explícita), mención expresa a la marca, inclusión de 
hashtags propios de la campaña y la ausencia o presencia del producto en la imagen compartida. Además, se calcula el engagement de dichas publicaciones con el propósito de conocer el grado de aceptación por parte de las comunidades de dichos influencers, así como la afinidad generada entre ellos.

Tabla 1. Muestra de análisis.

\begin{tabular}{|c|c|c|c|}
\hline Influencer & $\begin{array}{l}\text { Número de } \\
\text { seguidores }\end{array}$ & $\begin{array}{l}\text { ¿Influencer nativo } \\
\text { o no nativo? }\end{array}$ & $\begin{array}{c}\text { Motivo por el que se le } \\
\text { conoce (caso de los no } \\
\text { nativos) }\end{array}$ \\
\hline $\begin{array}{l}\text { Georgina Rodríguez } \\
\text { (@georginagio) }\end{array}$ & 19,2 millones & No nativo & $\begin{array}{l}\text { Relación sentimental con el } \\
\text { futbolista Cristiano Ronaldo. }\end{array}$ \\
\hline $\begin{array}{l}\text { Pilar Rubio } \\
\text { (@pilarrubio_oficial) }\end{array}$ & 4,8 millones & No nativo & $\begin{array}{l}\text { Presentadora, actriz y modelo } \\
\text { española. }\end{array}$ \\
\hline $\begin{array}{l}\text { Estefanía Unzu } \\
\text { (@verdeliss) }\end{array}$ & 1,2 millones & Nativo & - \\
\hline $\begin{array}{l}\text { Laura Matamoros } \\
\text { (@_Imflores) }\end{array}$ & $887 \mathrm{mil}$ & No nativo & $\begin{array}{l}\text { Familiar de personajes } \\
\text { públicos: hija del colaborador } \\
\text { de televisión Kiko Matamoros } \\
\text { y sobrina de la modelo y actriz } \\
\text { Mar Flores. }\end{array}$ \\
\hline $\begin{array}{l}\text { Adara Molinero } \\
\text { (@adara_molinero) }\end{array}$ & $858 \mathrm{mil}$ & No nativo & $\begin{array}{l}\text { Concursante de reality } \\
\text { (Gran Hermano) }\end{array}$ \\
\hline $\begin{array}{l}\text { Rocío Camacho } \\
\text { (@rocioccamacho) }\end{array}$ & $607 \mathrm{mil}$ & Nativo & - \\
\hline $\begin{array}{l}\text { Pablo Pérez } \\
\text { (@blon_doblefilo) }\end{array}$ & $617 \mathrm{mil}$ & No nativo & $\begin{array}{l}\text { Freestyler en Batallas de } \\
\text { Gallos }\end{array}$ \\
\hline $\begin{array}{l}\text { Azahara Luque } \\
\text { (@curly.azahara) }\end{array}$ & $584 \mathrm{mil}$ & No nativo & $\begin{array}{l}\text { Concursante de reality } \\
\text { (Gran Hermano) }\end{array}$ \\
\hline $\begin{array}{l}\text { Lucía Galán } \\
\text { (@luciamipediatra) }\end{array}$ & 295 mil & Nativo & - \\
\hline $\begin{array}{l}\text { Marian García } \\
\text { (@boticariagarcia) }\end{array}$ & 259 mil & Nativo & - \\
\hline
\end{tabular}

* Nota: número de seguidores comprobado en mayo de 2020.

Fuente: elaboración propia

\section{DISCUSIÓN}

\subsection{Internet y el ámbito de la salud}


Desde que en la década de los ochenta se produjo la consolidación de Internet, se instala en la sociedad "un instrumento de comunicación modal, interactiva, horizontal, global, libre y no controlado" (Castells, 2003, p. 8) con el que las personas han logrado generar y acceder a información digitalizada. A partir de este fenómeno, se ha producido una reestructuración en las construcciones sociales hasta generar una cultura de la autonomía (Castells, 2003).

El ámbito de la salud, inmerso en las características propias del contexto digital, también ha sufrido estas alteraciones. Como explica Monteagudo (2001), el efecto tanto de Internet, como de las "tecnologías digitales de comunicación, va mucho más allá que la implantación en la red de portales de salud dirigidos a consumidores o profesionales" (p. 25). Con lo que, al abordar la relación entre salud e Internet puede realizarse bajo distintas perspectivas, surgiendo así conceptos como:

- E-salud: referido al conjunto de herramientas e infraestructuras aportadas por las redes digitales con el propósito de prevenir, diagnosticar o gestionar el modo de vida en relación con la salud (Monteagudo, 2001; Cernadas et al., 2019).

- Informática Médica: campo científico enfocado al análisis de datos médicos, así como a su almacenamiento, recuperación y uso para resolver problemas y tomar decisiones (González y Molina, 2003).

- Telemedicina: prestación de servicios de salud a distancia mediante servicios interactivos de consulta y diagnóstico (DeCS, s.f.).

Con lo que, por un lado, se ha modificado la manera en la que las personas ajenas al campo de la medicina acceden a informaciones de naturaleza sanitaria y, por otro, sucede que los distintos agentes que participan en las prácticas sanitarias (médicos, enfermeras, farmacéuticos, pacientes, etc.) intercambian información entre sí vía online. Concretamente, Díaz de León (2019) indica cómo los actores que pueden "adoptar y apropiarse de las TIC con fines de salud" son la población general y "los prestadores de servicios de salud (ya sean profesionales o técnicos)" (p. 179).

De hecho, actualmente las actividades, servicios y sistemas inscritos en la e-salud con los que se procura fomentar "la salud, la lucha contra las enfermedades y la atención sanitaria a nivel mundial" (Rodríguez, 2019, p. 28) abarcan un espectro de actividades diferente al de hace unos años. Esto se debe a la irrupción de ciertas prácticas a través de redes sociales, donde los usuarios han adquirido un "papel activo e incluso protagonista en la difusión de mensajes online", generando un modelo de autonomía mediática denominado autocomunicación (Campos et al. 2010).

\subsection{Nuevas estrategias de e-salud}

Gracias al cambio de paradigma en el que los medios de comunicación verticales mutan a redes horizontales (Castells 2009; Campos et al. 2010), se ha fomentado una cultura participativa en torno a la creación y difusión del conocimiento. 
La cultura participativa permite que las personas compartan en el mundo virtual una serie "de ideas, perspectivas, tendencias, actitudes, etc.", tal y como explican GarcíaNúñez y García-Huerta (2018, p. 458), que tendrán repercusión en el mundo real. Así, este tipo de comunicación interactiva y múltiple repercutirá de forma acentuada a la hora de que un usuario pruebe un producto, un servicio o realice ciertas prácticas.

Para Hartzband y Groopman (2010), nada ha revolucionado más la práctica de la medicina que la aparición de Internet ya que, desde la normalización de su uso, los pacientes acceden a información que, en el pasado, solo estaba bajo el control de los profesionales de la salud. En relación con este cambio en la medicina provocado por la influencia de Internet sobre la información de salud, Wilson y Risk (2002) expusieron durante los primeros años en los que comenzaba a estudiarse este fenómeno, su preocupación ante el hecho de que la gran cantidad de información disponible en Internet dificultase el acceso del usuario a aquella de mejor calidad.

El término infobesidad, traducido del inglés information overload, hace referencia, tal y como indican Jaubert y Dolbeau-Bandin (2020), a la sobrecarga informativa provocada por la saturación de información procedente del exterior. En consecuencia, en el campo de la información sanitaria, el usuario no sólo padece saturación al recabar datos inútiles, erróneos e incompletos, sino que, además, pone en duda a los facultativos que posteriormente les atienden (Salud sin Bulos y Doctoralia, 2019).

De hecho, uno de los argumentos encontrados por parte de los pacientes para no utilizar esta fuente es precisamente que ha sido desaconsejado por los propios profesionales de la salud (Abt-Sacks et al., 2013). Sin embargo, con el paso de los años, el uso de esta herramienta ha ido aumentando dado que el número de búsquedas relacionadas con salud asciende cada vez más (Villaescusa et al., 2013).

Concretamente, según los datos de Eurostat (2020), en España en 2019, un 60\% de la población recurrió a Internet para buscar información sobre temas de salud, cinco puntos por encima de la media de la Unión Europea, que cuenta con un 55\% (Eurostat, 2020). Pero si hay una situación en la que la búsqueda de información sobre salud ha aumentado exponencialmente ha sido durante la pandemia provocada por la Covid-19. Según datos de Comscore (2020), el uso se disparó la semana del 24 de febrero de 2020 al 1 de marzo de 2020, cuando el peligro del virus comenzaba a verse como una posible realidad. En el caso de España, la búsqueda de información de salud se ha incrementado durante la pandemia un $66 \%$ respecto a la situación previa al Covid-19 comparándolo con datos de la semana del 30 de diciembre de 2019 al 5 de enero de 2020.

Vinculado con esto, cabe destacar que, a raíz de esta crisis sanitaria, ha surgido el término infodemia. Según Aguado-Guadalupe y Bernaola-Serrano (2020), la sobresaturación de información y la rápida difusión de esta, unido a la desinformación, "ha provocado que la Organización Mundial de la Salud (OMS) tuviera que advertir sobre la amenaza de los rumores, bulos y datos falsos que se estaban propagando, dando lugar a lo que se ha denominado infodemia" (p. 290). De hecho, "la situación llevó a la OMS (...) a habilitar en su web un apartado para desmentir los mitos que circulaban por redes 
sociales" (Aguado-Guadalupe y Bernaola-Serrano, 2020, p. 290-291). Se corrobora, por tanto, que las redes sociales no son el medio más adecuado para encontrar información fiable sobre cuestiones sanitarias; hasta el punto de que la OMS ha tenido que intervenir para intentar paliar la oleada de bulos que circulaban a través de estas en lo relativo a la Covid-19.

Esto guarda relación con lo que señala Khan (2020), que afirma que la información y el contenido superfluo desplazó a un segundo plano a la información útil y esencial que se difundía en redes sociales sobre la Covid-19. Aquí encontramos otro aspecto interesante, y es el hecho de que la poca información útil que se comparte en redes sociales pasa desapercibida frente a otro tipo de contenidos.

\subsection{Motivos por los que consultar información sanitaria}

La conducta por la cual la población consulta información sobre temas de salud en Internet, expone Solé (2003), halla su justificación en la posibilidad de acceder de forma gratuita a conocimiento que no solo procede de profesionales, sino del conjunto de la ciudadanía, aun siendo conscientes de poder recibir información sin rigor científico. Por lo tanto, puede deducirse que el usuario valora la conversación online y el asesoramiento entre iguales gracias a los mecanismos que permiten la comunicación horizontal propia de la cultura participativa.

A pesar de los gustos o las tendencias de la ciudadanía, el acceso a la información que pone a disposición Internet en el ámbito de la salud es un debate que ha quedado demostrado en la literatura que se ha generado hasta el momento. Diversos estudios se han dedicado a analizar los efectos positivos y negativos que puede generar en la población el libre acceso a información de carácter sanitario (Santamaría-Ochoa et al., 2016; Sanz-Lorente y Castejón, 2019).

Explican Farré et al., (2012) que la Unión Europea ha revisado sus estrategias a la hora de difundir información científica para que su mensaje no pierda legitimidad o rigor en el entorno mediático contaminado por el uso ciudadano de las redes sociales (p. 381). A pesar de ello, hay que destacar que, gracias a Internet, es posible proveer a los usuarios de herramientas que les permiten tomar un papel activo en el cuidado de su salud. Algunos autores ya hablan del empoderamiento del paciente como uno de los principales aspectos positivos del impacto que tiene Internet en el ámbito de la salud (Hawn, 2009; Arantón, 2014).

Entre los beneficios de este empoderamiento, otros autores han concluido que "un paciente «bien informado» mejora su adherencia a los tratamientos y afronta la autogestión de su enfermedad de manera más autónoma y responsable, se hace necesario proveer a la población de páginas web sanitarias de calidad científica, adaptadas culturalmente" (Abt-Sacks et al., 2013, p. 246).

Además, muchos autores defienden la utilidad de Internet de cara a la planificación de servicios de salud y a la vigilancia en salud con los patrones observados por el tráfico de 
información compartida en Internet (Eysenbach, 2009). Incluso, podría afirmarse que en Internet se encuentra un campo de actuación por parte de los propios profesionales de la salud, teniendo a su disposición multitud de herramientas que les facilitan la interacción con los pacientes a modo de consulta online (Sanz-Lorente y Castejón, 2019). Por ejemplo, gracias a los avances tecnológicos nos encontramos con iniciativas como el proyecto Dejal@Bot, un "ensayo clínico independiente y realizado en Atención Primaria de Salud para ayudar a los pacientes a dejar de fumar asistidos por un chatbot" (ÁvilaTomás et al., 2019, p. 56). Cabe destacar también que a raíz de la Covid-19, la propia Atención Primaria pública de la Comunidad de Madrid ha recurrido a la tecnología y, en concreto la aplicación WhatsApp, para poder atender a sus pacientes sin necesidad de concertar una cita presencial.

En otro orden, la aparición de las comunidades de pacientes virtuales, indican Moreira y Camara (2012), impulsa la asimilación de conocimiento relacionado con la salud y ejemplifica el procedimiento en el que los pacientes adquieren independencia. Estos autores abordan la demostración empírica que revela que "uno de los orígenes de las causas de muerte de los pacientes es la falta de vínculos sociales o redes sociales de contactos" al repercutir las relaciones sociales sobre "la salud física y mental de los pacientes" (p. 49). Otros autores encuentran múltiples ventajas a estas redes de usuarios que "facilitan el apoyo emocional, el intercambio de información, experiencias y consejos de autoayuda e incluso la asistencia sanitaria cuando un profesional sanitario participa como moderador" (Jiménez-Pernett et al., 2007, p. 47). En contraposición, y pesar de lo señalado, autores como Leis et al. (2013) siembran la duda sobre la utilidad de grupos, como los de Facebook, al convertirse en un foco de informaciones promocionales entorno a productos como, por ejemplo, los dietéticos.

\subsection{Alfabetización en salud}

Ante el panorama virtual de embustes e intereses comerciales, se desarrolla en Solé (2003) que "la ética de la información sanitaria debe respetarse en la red, distinguiéndose con claridad lo que es información científica y lo que es publicidad" (p. 181), con lo que ha de identificarse a los autores, proporcionar las fuentes de información, informar sobre la fecha de actualización del espacio web, indicarse que el material aportado no sustituye el criterio de un médico y, por supuesto, si el portal está siendo patrocinado por una marca (p. 182).

Aunque una comunicación incorrecta por parte de la página web podría tener efectos nocivos en cualquier persona, a la hora de estimar los efectos que puede probar el fácil acceso a informaciones relativas a la salud, debe tenerse en cuenta la especial vulnerabilidad de los jóvenes que emplean Internet como una de sus principales maneras de obtener información al ser un medio rápido, gratuito y, a priori, confidencial.

Así, muchos autores coinciden en que entre las principales dificultades que pueden surgir en la búsqueda de información sobre salud, están, por un lado, las habilidades de los propios usuarios para buscar la información correcta (Henwood et al., 2003) y, por 
otro, la calidad de la información que los usuarios obtienen al hacer uso de la red (Martín et al., 2014; Sanz-Valero et al., 2006).

Con todo, resulta fundamental la implantación de la alfabetización en salud: AES. Un término traducido del inglés health literacy que, según Falcón y Luna (2012), surge como un concepto complejo durante los años 70 en el mundo anglosajón. Concretamente, los autores señalan que la OMS define a la AES como el conjunto de "habilidades sociales y cognitivas que determinan el nivel de motivación y la capacidad de una persona para acceder, entender y utilizar la información de forma que le permita promover y mantener una buena salud" (p. 92).

Falcón y Luna (2012) explican que dicho concepto atiende tanto a la capacidad del individuo para entender un prospecto o la información aportada por un profesional sanitarios, como a la facultad para "acceder a la información adecuada, interpretarla, juzgarla y aprovecharla para tomar decisiones bien fundamentadas". Por tanto, la AES resulta crucial para que los individuos actúen a favor de su salud y de la salud pública, ya que dependerá de "las capacidades individuales de los ciudadanos" (p. 92).

Pero, para que se produzca una mejoría en la AES, se demanda un "abordaje multifactorial, pluridisciplinar y multisectorial" que comprenda tanto la actuación educativa como la sanitaria para garantizar la optimización de las conductas ciudadanas. Es necesario reforzar "los cambios sostenibles en las conductas" con la colaboración de "la industria farmacéutica y de la alimentación, los medios de comunicación científicos y divulgativos, la representación de los colectivos de profesionales sanitarios, pacientes y usuarios, y, por supuesto, de aquellos con responsabilidades políticas" (Falcón y Luna, 2012, p. 97).

En este punto, en base a las aportaciones de Martínez y Sosa (2016), ha de diferenciarse entre la comunicación en salud y la comunicación para el desarrollo y el cambio social, ya que la primera se refiere a los mensajes de carácter comercial, y la segunda alude a aquella cuyo objetivo reside en erigir una sociedad saludable logrando un cambio en las relaciones de poder. Para la consecución de esta meta han de involucrarse todos los individuos y comunidades posibles. Sobre el origen de la comunicación para el desarrollo, Martínez y Sosa enuncian:

Surge de un proceso estratégico adoptado por agencias de cooperación internacional en la década de los 50, en los Estados Unidos la impulsó la United States Agency for International Development (USAID) y en las Naciones Unidas FNUAP a través de campañas de comportamiento para temas de nutrición y desarrollo humano. A su vez, FAO empleó la educación para la formación de agricultores y tecnologías agrícolas saludables y UNICEF para el bienestar de los niños y sus madres. Asimismo, la comunicación para el desarrollo basa sus intenciones en teorías psicosociales y de persuasión como de relaciones públicas centrándose en cambios de comportamiento individuales gracias a la difusión de mensajes a públicos con características convergentes (2016, p. 73).

\subsection{Marketing de influencia y educación en el campo de la salud}


Internet alberga diversos medios desde los que acceder a información sanitaria, ya sean los blogs, los foros, las redes sociales o las aplicaciones móviles, entre otros. Diferentes autores han analizado cada uno de estos, así como la influencia que tienen en la comunicación de salud.

Por ejemplo, se consideran una herramienta de uso edu-comunicativo aquellos blogs que, en el ámbito de la educación alimentaria y nutricional, despiertan el interés de los lectores y promuevan la salud de los individuos (Rojas et al., 2018). Las aplicaciones móviles de salud también son vistas como un aliado en la educación en salud, así como la creación de repositorios web en los que se incluyan fuentes de información fiables y seguras. Todo esto supone una nueva forma de empoderar y situar a los usuarios como eje central (Fernández y Ramos, 2013).

Precisamente sobre las aplicaciones móviles hablan Gil-Torres et al., (2020). En su trabajo, señalan que "los rasgos de discurso predominantes en las apps sobre el COVID19 fueron, de manera predecible, aquellas vinculadas con la salud y la información" (p. 350). De hecho, los autores subrayan el hecho de que "las aplicaciones informativas hayan sido más demandadas" (p. 351) teniendo en cuenta la gran cobertura mediática que se le ha otorgado a la pandemia provocada por la Covid-19. Vemos, por tanto, que la gente ha recurrido a la tecnología para buscar información sanitaria, al igual que ha ocurrido en las redes sociales. Las aplicaciones móviles, como se demuestra, juegan un importante papel también en la educación sanitaria online.

Pero sin duda alguna, las redes sociales son plataformas que, una vez analizadas, varios autores encuentran como sistemas de empoderamiento del paciente. Por eso, en el año 2009 la Organización Mundial de la Salud anunciaba la aparición de las redes sociales como una nueva área en evolución, con lo que urgía la presencia en éstas de profesionales de la salud para proveer a los ciudadanos de información verídica. Lo que significaba "una oportunidad para los profesionales de la salud para explorar, escuchar y atraer” (McNab, 2009, p. 566).

En este punto confluyen dos realidades, ya que las redes sociales no son un mero espacio para la propagación de contenidos. Como enuncia Castelló (2010), el receptor ya no ocupa solo el puesto de público, sino que "además de consumidor-productor (crossumer), el fan de la marca (fansumer) se convierte en un consumidor profesional (prosumer)". Por lo que las marcas no solo se sirven de la clásica y orgánica difusión ejercida por el consumidor anónimo, sino que se benefician de los líderes de opinión del medio online capaces de generar repercusión sobre su producto y de difundir, en consecuencia, un punto de vista sobre una empresa, marca o producto concreto.

Es cierto que, con anterioridad a la aparición y normalización de las redes sociales, las marcas ya se servían de los medios de comunicación y de las personas influyentes. Sin embargo, con la horizontalización de las estructuras comunicativas y el fenómeno del marketing de influencia, se simplifica la manera en la que las marcas acceden a sus públicos de interés. 
Las campañas publicitarias del sector salud, detalla Álvarez (2014), siempre han contado con un escaso atractivo desde el punto de vista de las agencias. En primer lugar, por la restrictiva reglamentación que recae sobre este tipo de campañas y, en segundo lugar, porque hasta no hace demasiado tiempo "los responsables de comunicación de los laboratorios y productos de salud solían ser médicos y farmacéuticos, poco expertos en publicidad y comunicación" (p. 109).

Sin embargo, durante los últimos años el sector publicitario ha procurado generar productos más próximos al consumidor. Así, en el artículo de Álvarez (2014) se destaca la creación de la Asociación Española de Agencias de Publicidad de Salud o la Cátedra de Comunicación y Salud en la Facultad de Ciencias de la Información de la Universidad Complutense. En este contexto, los últimos años han abierto la puerta a estrategias de marketing de influencers, una de las formas que utilizan las empresas para llegar a sus públicos objetivos.

\subsection{Los influencers y las recomendaciones sobre hábitos de salud}

Para puntualizar este concepto, según el Interactive Advertising Bureau España (IAB), los influencers son aquellas personas "que tienen el potencial de crear engagement, impulsar la conversación y/o influir en la decisión de compra de productos/servicios a un público objetivo" (IAB Spain, 2019). Este tipo de marketing es una nueva forma de trasladar el boca-oído al entorno digital (Dueñas et al., 2020) y de generar un marketing viral que no se dirige a clientes individuales, sino a redes de clientes (Aguado y García, 2009).

Con ánimo de identificar los efectos que pueden tener los influencers en sus seguidores, Pilgrim y Bohnet-Joschko (2019) establecieron tres categorías: transferencia de conocimiento, benevolencia e identificación personal, siendo esta última donde se hallan aquellos seguidores con una mayor sensación de familiaridad percibida con el influencer, hasta el punto de requerir su consejo como si de un amigo se tratase.

Existen cada vez más artículos que investigan el fenómeno de los influencers y que tratan de profundizar en su relación con los procesos de consumo (Dueñas et al., 2020), puesto que se ha observado que Internet es uno de los canales que más influye en las decisiones de compra, así como las recomendaciones hechas por una persona conocida, como los influencers (Castelló-Martínez y Del Pino Romero, 2015).

En relación con esto, en el informe Libro Blanco de Marketing de Influencers del IAB Spain (2019), se apunta cuán determinante resulta que los influencers sean reconocidos en su nicho más especializado para que los anunciantes recurran a ellos a la hora de abordar una temática en la que estos sean líderes de opinión: gaming, lifestyle, música, deporte, cocina, etc.

Teniendo en cuenta, por un lado, que se ha engendrado un nuevo enfoque sobre la relación entre consumidor-marca/producto y, por otro, que actualmente la ciudadanía 
recurre a Internet para realizar consultas sanitarias, contrastar informaciones o conocer nuevas prácticas relacionadas con la salud, los líderes de opinión han visto en este campo un nicho sobre el que actuar.

Respecto a estas recomendaciones sobre hábitos de salud, cabe destacar que, según Byrne, Kearney y MacEvilly (2017), el marketing de influencia desempeña un papel fundamental en la salud pública. Los autores hacen hincapié en que los influencers cada vez tienen más poder a la hora de cambiar el comportamiento de sus seguidores en torno a la elección de alimentos y dieta. En su estudio (Byrne, Kearney y MacEvilly, 2017) revelan que los influencers motivan a sus seguidores a llevar una dieta más saludable. Sin embargo, reiteran la escasa calificación y rigor científico en el que se basan para hacer estas recomendaciones, compartiendo así información falsa o engañosa y que puede afectar negativamente a la salud de sus seguidores, ya que algunas personas siguen consejos sobre dietas ausentes de gluten o lácteos sin tener en cuenta el efecto que pueda tener para su salud. De hecho, Baudrillart et al., (2018) se cuestionan la calidad de la información compartida por influencers en materia de salud.

Respecto a la clasificación de influencers del sector de la salud, Ferret (2019) indica que los perfiles a los que más recurren las marcas son aquellos de "vida sana, recetas healthy, deportistas o madres preocupadas por el bienestar de la familia". Por su parte, Deprez (2016) se enfoca en los influencers especializados en el dominio farmacéutico y, por tanto, visibiliza algunas fuentes de información fiables sobre salud.

En relación con el ámbito alimenticio, y motivados por el incremento de la obesidad infantil, numerosos investigadores han comenzado a interesarse por los hábitos alimenticios en los más jóvenes y su relación con la aparición de comidas no saludables presentadas por influencers (Coates et al., 2019). De hecho, vinculado con la calidad de la información, es importante mencionar que un estudio escocés presentado en el Congreso Europeo de Obesidad ha demostrado que solo uno de cada nueve influencers cumplía con los criterios necesarios para divulgar información relacionada con la salud (El País, 2019).

Ligado al ámbito de la alimentación también se encuentra el concepto del ideal de belleza que puede ser reflejado en el contenido y los propios comentarios de las redes sociales de muchos influencers. Es precisamente desde el enfoque de los trastornos alimenticios donde autores como Larrain y Arrieta (2010) han analizado este concepto fomentado principalmente por los medios de comunicación.

En nuestra cultura actual, belleza y delgadez son dos conceptos que están estrechamente relacionados. Seva y Casadó (2015), conscientes del papel de los medios de comunicación en el fomento del ideal de belleza femenino, encontraron en el análisis de publicaciones en revistas y redes sociales, una figura aceptada socialmente como el "cuerpo ideal" que es difícilmente alcanzable, simplemente por genética, y que repercute en las inseguridades de las seguidoras de estos perfiles. 
Pero los hábitos alimenticios no son el único tema de salud del que hablan los influencers, puesto que también se han dado casos en los que éstos recomiendan la utilización de determinados fármacos. En España, los organismos sanitarios han comenzado a observar un aumento de estas prácticas, con lo que a finales de 2019 y principios de 2020 fueron publicadas varias noticias en medios españoles alertando sobre la creciente demanda en farmacias de medicamentos recomendados por influencers (Redacción Médica, 2019; Linde, 2020; García, 2020).

El Ministerio de Sanidad comenzaba a intervenir en este problema en el mes de noviembre de 2019, trabajando con Google y las redes sociales para que fueran eliminados este tipo de contenidos (Negrete, 2019). Previamente, el Consejo General de Colegios Oficiales de Médicos, el Consejo General de Colegios Oficiales de Farmacéuticos y el Consejo General de Colegios de Dentista, ya se habían unido por esta problemática, para recordar que estas acciones suponen un riesgo para la salud de los pacientes (Redacción Médica, 2020). Por su parte, el Consejo General de Colegios Oficiales de Farmacéuticos ha elaborado una campaña contra la desinformación generada en redes sociales y para "advertir de los riesgos de medicamentos que se publicitan sin ningún control por parte de los llamados influencers (...) sin formación científica", así como un argumentario respondiendo a los principales problemas encontrados con la información de medicamentos en redes sociales (Cgcof, 2020).

Por otro lado, el estudio de Isorna, De la Cruz y Villanueva (2020) se centra en cómo las tabaqueras utilizan a influencers jóvenes y populares para publicar fotografías en las que salen fumando "como parte de una estrategia de marketing documentada en más de 40 países" (p. 104). En España, a pesar de estar prohibida la publicidad de tabaco, a menudo puede comprobarse cómo la ley es quebrantada, tal y como sucede con la publicidad relacionada con el alcohol. Vinculado con el tabaco, también encontramos en las redes sociales numerosos influencers recomendando tiendas o marcas de vappers (figura 1), fomentando el uso de estos cigarrillos electrónicos sin hacer ningún tipo de mención a los riesgos de consumir estas sustancias.

No obstante, no solo se recurre a los influencers para hacer publicidad de productos como tal, sino que también se recurre a ellos para informar sobre iniciativas o campañas vinculadas con la salud. Es el caso de la campaña \#Diabetesportucorazón, en la que Lilly y Boehringer Ingelheim unieron a médicos, pacientes, periodistas e influencers en un "workshop cardiosaludable" para que Alberto Chicote cocinase recetas cardiosaludables (Lilly, 2020). Este acontecimiento sirvió para que numerosos influencers compartiesen consejos e información en sus redes sociales sobre la Diabetes de tipo 2 (DM2).

\subsection{Ejemplos de influencers y sus recomendaciones sobre hábitos de salud}

Las recomendaciones que los influencers realizan suelen ser sobre productos de uso diario. De esta forma, se pretende generar en los seguidores una sensación de credibilidad al supuestamente atestiguar los resultados de un determinado artículo. Los productos vinculados a la salud no son una excepción, con lo que las figuras públicas comparten información que, aparentemente, mejora la educación en salud de sus 
seguidores. Ha de tenerse en cuenta que la información que estas personas difunden no siempre es veraz, puesto que los intereses publicitarios y económicos tiznan el contenido de conveniencias personales. En consecuencia, si los seguidores no detectan o restan importancia a este factor, aceptarán e interiorizarán información sin rigor científico o poco fiable.

Analizando las publicaciones sobre salud de algunas personas influyentes en España, puede comprobarse cómo se habla a favor de ciertos medicamentos, suplementos vitamínicos, farmacias online, aplicaciones móviles de salud, etc. Así, a continuación, procede a ejemplificarse este fenómeno mediante diversos contenidos extraídos de la plataforma de Instagram.

En agosto de 2019, la influencer Rocío Camacho (@rocioccamacho) indicaba los resultados de haber utilizado el fotoprotector Hydro Oil de la marca Isdin desde principios del verano y, además, lo recomendaba por favorecer un "bonito" y "saludable" bronceado (figura 2). No obstante, en junio del mismo año, publicaba cómo iba preparando su piel para el verano con otra crema solar. Esta vez de la marca Lancaster Beauty (figura 3). En este post, Camacho también explicaba cómo el producto protegía la piel y permitía un "bronceado bonito y saludable". Con más de 600.000 seguidores, las marcas recurren a ella para conseguir cobertura y afinidad en su comunicación, sin tener ni siquiera en cuenta su colaboración con marcas de la competencia. Sus seguidores, no obstante, sí que se ven bastante impactados ante la publicidad de diferentes marcas de protector solar en el mismo margen de tiempo. Es clave destacar el hecho de que a estos productos se les considere "saludables" sin ni siquiera explicar el motivo de por qué lo son.

Por otro lado, Azahara Luque (@curly.azahara), exconcursante del reality Gran Hermano 15, animaba a sus seguidores a través de las historias de Instagram en mayo de 2020 a usar una aplicación de telemedicina Ilamada Savia (figura 4). Para ello, explicaba todas las especialidades médicas disponibles en la aplicación y compartía su experiencia con sus más de 580.000 followers al comentar lo bien que le estaba viniendo la aplicación para contactar con médicos en un momento en el que sufría mastitis y los centros de salud estaban cerrados por la Covid-19.

Por otro lado, nos encontramos con los ejemplos de los blanqueamientos dentales, que son tendencia en redes sociales y cada vez más jóvenes recurren a ellos a pesar de no tener prácticamente información sobre sus beneficios y riesgos. Así, Georgina Rodríguez (@georginagio), actual pareja del futbolista Cristiano Ronaldo, recomienda con frecuencia en Instagram el blanqueador dental Hi Smile (figura 5), a pesar de que los dentistas señalan que es necesario que los pacientes se hagan un reconocimiento previo para darles un diagnóstico adecuado antes de someterse a este tipo de tratamientos (Tardón, 2015). Este suceso cobra especial importancia cuando los consejos de la celebrity alcanzan a más de 19 millones de personas de todo el mundo.

El perfil de la presentadora y modelo Pilar Rubio (@pilarrubio_oficial) acoge imágenes de su día a día, generalmente fotos de sus rutinas deportivas, sus embarazos, su familia o su trabajo. En esta línea, relacionada con la maternidad y el entrenamiento físico, en

Revista de Comunicación y Salud, 2021, Vol. 11, 19-57 
enero de 2020 Rubio anunciaba un complemento alimenticio que recomendaba junto a ejercicio y una dieta saludable (figura 6); y en marzo del mismo año publicaba una imagen (figura 7) de la tercera edición de Embarazada ¿y ahora qué?, el libro sobre cuidados durante y tras el embarazo que coescribe con Caroline Correia. Es importante destacar el hecho de que una reportera, modelo y presentadora se convierta en coautora de un libro de consejos para el embarazo, un tema muy delicado y del que se le ha proclamado experta, no por su formación académica, sino por su experiencia personal.

La influencer Estefanía Unzu, con más de un millón de seguidores, es una youtuber conocida por compartir en su canal Verdeliss el día a día de su familia numerosa, así como por participar en el reality show Gran Hermano Vip. En su perfil de Instagram (@verdeliss) nos encontramos con recomendaciones sobre productos vinculados al cuidado de sus hijos. Una de ellas es del producto BabyRub que, aunque no es un medicamento como tal, sí que se utiliza para la congestión o el resfriado de los bebés (figura 8). De igual manera, también hace recomendaciones de los productos Femibion, unos polivitamínicos para la lactancia y el embarazo (figuras 9 y 10). De estos posts es especialmente reseñable el hecho de que comparta información médica importante como "ayuda a la formación normal de hormonas tiroideas y a la función de la tiroides" o recomendar simultáneamente la ingesta de ácido fólico durante el embarazo "para cubrir los 400mgc y así ayudar a un correcto desarrollo del tubo neural del bebé". Esta información es muy específica y no la debería difundir alguien que no es experto en la materia pues, los seguidores, al leer esto, hacen que su confianza en ella crezca y confíen ciegamente en lo que comparte a pesar de no tener ningún tipo de formación en ciencias de la salud.

Otro ejemplo lo encontramos en la publicidad de los productos Fitvia (té con estimulantes). Adara Molinero, exconcursante de reality shows de televisión, publicaba en junio de 2019 una foto (figura 10) consumiendo este producto y recomendándole en relación a su recuperación post-parto. Señalaba que este producto activa el metabolismo y favorece la quema de calorías. Por su parte, Rocío Camacho, recomienda otro té diferente de la misma marca (figura 12), "perfecto para depurar toxinas" y "eliminar retención de líquidos". Como se puede observar, la estrategia de comunicación de la marca se basa en el marketing de influencia para intentar mostrar el producto como un agente regulador y healthy. A pesar de ser un producto de consumo, y no un medicamento, guarda relación con la salud, sobre todo teniendo en cuenta el texto que acompaña a las publicaciones que acabamos de presentar, en el que se muestra cómo el producto puede contribuir con la salud de los consumidores en función del sabor elegido.

En referencia a la pandemia provocada por la Covid-19, puede señalarse como ejemplo el caso de Laura Matamoros (@_Imflores), una influencer de moda, que compartía en su perfil que se había realizado la prueba de anticuerpos de Covid-19 y el resultado positivo de la misma. Junto a esta noticia (figura 13), señalaba su alegría al haber generado anticuerpos y, en consecuencia, volverse inmune a la enfermedad. El principal problema de estas declaraciones es que en ese momento todavía no se sabía con seguridad si el hecho de padecer la enfermedad genera a posteriori la inmunidad que 
Matamoros comenta. De modo que, información sin rigor científico puede calar, con seguridad, en un alto número de personas teniendo en cuenta los más de sus 880.000 seguidores de Instagram. A fin de cuentas, este caso no es más que un ejemplo de cómo las recomendaciones de los influencers pueden transmitir datos que alejen a los seguidores de las nociones verídicas en torno a un tema.

La cantidad de influencers que fomentan cierto tipo de comportamientos de consumo, está intrínsecamente relacionado con la imagen de cuerpo ideal que, tal y como indican Seva y Casadó (2015), fomenta el hecho de que en Internet se aborden "actitudes y actividades relacionadas con el culto al cuerpo" (p. 71). En este apartado se inscribe la promoción de "dietas, ejercicio físico abundante, productos de belleza milagrosos, trucos para adelgazar" y una larga lista de aplicaciones móviles, entre otros consejos (p. 71).

A partir de todos estos ejemplos, es importante subrayar las palabras de Carlos Mateos (Cgcof, 2020), coordinador de la campaña \#SaludsinBulos, que menciona que "la mayoría de influencers comparte sus contenidos a través de Instagram, cuyas publicaciones son más efímeras y difíciles de rastrear", haciendo referencia a las publicaciones en stories, como la de Azahara Luque de la aplicación móvil o la de Laura Matamoros sobre el coronavirus Covid-19.

Además, respecto a la recomendación de medicamentos en redes sociales, Guillermo Martín, propietario de la cuenta @farmacia_enfurecida, afirma que la prescripción y el consumo de medicamentos es un delito (según el Real Decreto 1416/1994) ya que puede causar alergias, reacciones, saturación en los centros médicos equivocaciones como confundir un antibiótico con un cosmético, como ocurre con ciertos champús o toallitas. Este suceso, enuncia Martín, es una práctica sancionable en Google y YouTube, pero en Instagram, "donde se haya el grueso de los influencers", aún no se han tomado medidas (iSanidad, 2020).

Análogamente, podemos encontrar profesionales que comparten información con utilidad y rigor científico a través de las redes sociales. Como ya hemos mencionado, la OMS creía necesaria la presencia de profesionales de la salud en las redes sociales para ofrecer información verídica en estas plataformas (McNab, 2009). Por tanto, el hecho de que los profesionales se impliquen en la educación en salud a través de las redes sociales es algo muy positivo para los pacientes en particular y ciudadanos en general, ya que se trata de información veraz, rigurosa, y al alcance de la mayor parte de la población.

En la muestra del presente estudio encontramos dos ejemplos. Por un lado, el caso de la doctora Lucía Galán (@lucíamipediatra) con más de 290.000 seguidores. Esta pediatra y miembro del Consejo Asesor de Unicef, ha escrito seis libros, y a través de su Instagram comparte noticias, consejos y estudios recientes que puedan influir en la salud de los niños. Como el resto, Galán también ha hecho referencia a la Covid-19, pero centrándose en los más pequeños. En la mayoría de los casos, Galán utiliza Instagram para compartir parte de la información que posee, pero normalmente redirige a sus seguidores a su página web personal, donde comparte el contenido completo de sus artículos o investigaciones. 
Por otra parte, encontramos a la farmacéutica Marian García (@boticariagarcia), que cuenta con más de 250.000 seguidores. Al igual que Galán y a diferencia de los perfiles mencionados anteriormente, la administradora de este perfil cuenta con formación en el ámbito de la salud, y demuestra su conocimiento no solo compartiendo información a través de las redes sociales, sino que también colabora en divulgarlo en otros medios (radio, prensa, televisión...). De hecho, García ha colaborado en varias ocasiones en Zapeando, el programa de sobremesa de La Sexta. En su perfil comparte noticias e información de interés vinculada con la Covid-19. Sin embargo, antes de que surgiese esta crisis sanitaria ya compartía noticias de interés del sector, así como consejos y bulos sobre alimentación y hábitos saludables.

Un aspecto que hay que señalar sobre estos perfiles es que las publicaciones patrocinadas son mínimas, al contrario que en el resto de los perfiles. Los profesionales, al fin y al cabo, pretenden divulgar información y educar a la población en salud a través de las redes sociales. Sin embargo, los influencers no profesionales hacen promociones de productos vinculados con la salud sin ningún tipo de conocimiento científico, por lo que la información ofrecida por ellos es más comercial y menos divulgativa.

Tabla 2. Datos recogidos a partir de los perfiles de la muestra que difunden contenido promocional.

\begin{tabular}{|c|c|c|c|c|c|c|c|}
\hline $\begin{array}{l}\text { Figu } \\
\text { ra }\end{array}$ & Influencer & $\begin{array}{c}\text { Contenid } \\
0\end{array}$ & $\begin{array}{c}\text { ¿Publicid } \\
\text { ad } \\
\text { explícita? }\end{array}$ & $\begin{array}{c}\text { ¿Menci } \\
\text { onan el } \\
\text { perfil de } \\
\text { Instagra } \\
\text { m de la } \\
\text { marca? }\end{array}$ & $\begin{array}{c}\text { ¿Se } \\
\text { incluye } \\
n \\
\text { hashtag } \\
\text { s } \\
\text { propios } \\
\text { de la } \\
\text { campañ } \\
\text { a? }\end{array}$ & $\begin{array}{c}\text { ¿Se } \\
\text { muestra } \\
\text { el } \\
\text { product } \\
\text { o en la } \\
\text { imagen } \\
\text { compar } \\
\text { tida? }\end{array}$ & $\begin{array}{c}\text { Seguidores/ } \\
\text { Likes de la } \\
\text { publicación/ } \\
\text { Engagement } \\
\text { de la } \\
\text { publicación }\end{array}$ \\
\hline $\begin{array}{l}\text { Figur } \\
\text { a } 1\end{array}$ & $\begin{array}{l}\text { Pablo Pérez } \\
\text { (@blon_doblefil } \\
\text { o) }\end{array}$ & Vappers & Sí (\#Ad) & Sí & Sí & Sí & $\begin{array}{l}617 \mathrm{mil} / \\
38.897 / \\
6,30 \%\end{array}$ \\
\hline $\begin{array}{l}\text { Figur } \\
\text { a } 2\end{array}$ & $\begin{array}{l}\text { Rocío Camacho } \\
\text { (@rocioccamac } \\
\text { ho) }\end{array}$ & $\begin{array}{l}\text { Fotoprote } \\
\text { ctor } \\
\text { Hydro Oil }\end{array}$ & Sí (\#Ad) & Sí & Sí & Sí & $\begin{array}{l}607 \mathrm{mil} / \\
20.102 / \\
3,31 \%\end{array}$ \\
\hline $\begin{array}{l}\text { Figur } \\
\text { a } 3\end{array}$ & $\begin{array}{l}\text { Rocío Camacho } \\
\text { (@rocioccamac } \\
\text { ho) }\end{array}$ & $\begin{array}{l}\text { Fotoprote } \\
\text { ctor } \\
\text { Lancaster } \\
\text { Beauty }\end{array}$ & Sí (\#Ad) & Sí & Sí & Sí & $\begin{array}{l}607 \mathrm{mil} / \\
24.360 / \\
4,01 \%\end{array}$ \\
\hline $\begin{array}{l}\text { Figur } \\
\text { a } 4\end{array}$ & $\begin{array}{l}\text { Azahara Luque } \\
\text { (@curly.azahar }\end{array}$ & $\begin{array}{l}\text { App de } \\
\text { telemedici }\end{array}$ & Sí & Sí & Sí & $-^{2}$ & \\
\hline
\end{tabular}

${ }^{2}$ No se trata de un producto, sino de un servicio. 


\begin{tabular}{|c|c|c|c|c|c|c|c|}
\hline & a) & $\begin{array}{l}\text { na } \\
\text { Savia }\end{array}$ & & & & & $584 \mathrm{mil} /{ }^{3}$ \\
\hline $\begin{array}{l}\text { Figur } \\
\text { a } 5\end{array}$ & $\begin{array}{l}\text { Georgina } \\
\text { Rodríguez } \\
\text { (@georginagio) }\end{array}$ & $\begin{array}{l}\text { Blanquea } \\
\text { dor dental } \\
\text { Hi Smile }\end{array}$ & Sí & Sí & No & Sí & $\begin{array}{l}19,2 \text { millones/ } \\
751.030 / \\
3,95 \%\end{array}$ \\
\hline $\begin{array}{l}\text { Figur } \\
\text { a } 6\end{array}$ & $\begin{array}{l}\text { Pilar Rubio } \\
\text { (@pilarrubio_ofi } \\
\text { cial) }\end{array}$ & $\begin{array}{l}\text { Complem } \\
\text { ento } \\
\text { alimentici } \\
\text { o } \\
\text { Ensure } \\
\text { Max } \\
\text { Protein }\end{array}$ & Sí (\#Ad) & No & Sí & Sí & $\begin{array}{l}4,8 \text { millones/ } \\
139.418 / \\
2,90 \%\end{array}$ \\
\hline $\begin{array}{l}\text { Figur } \\
\text { a } 7\end{array}$ & $\begin{array}{l}\text { Pilar Rubio } \\
\text { (@pilarrubio_ofi } \\
\text { cial) }\end{array}$ & $\begin{array}{l}\text { Libro } \\
\text { Embaraza } \\
\text { da ¿y } \\
\text { ahora } \\
\text { qué? }\end{array}$ & Sí & $\mathrm{Si}^{4}$ & No & Sí & $\begin{array}{l}4,8 \text { millones/ } \\
41.440 / \\
0,86 \%\end{array}$ \\
\hline $\begin{array}{l}\text { Figur } \\
\text { a } 8\end{array}$ & $\begin{array}{l}\text { Estefanía Unzu } \\
\text { (@verdeliss) }\end{array}$ & $\begin{array}{l}\text { Ungüento } \\
\text { Reconfort } \\
\text { ante } \\
\text { BabyRub }\end{array}$ & Sí (\#Ad) & No & Sí & Sí & $\begin{array}{l}1,2 \text { millones/ } \\
64.584 / \\
5,38 \%\end{array}$ \\
\hline $\begin{array}{l}\text { Figur } \\
\text { a } 9\end{array}$ & $\begin{array}{l}\text { Estefanía Unzu } \\
\text { (@verdeliss) }\end{array}$ & $\begin{array}{l}\text { Complem } \\
\text { ento } \\
\text { alimentici } \\
\text { o } \\
\text { Femibion }\end{array}$ & Sí (\#Ad) & No & No & Sí & $\begin{array}{l}1,2 \text { millones/ } \\
40.957 / \\
3,41 \%)\end{array}$ \\
\hline $\begin{array}{l}\text { Figur } \\
\text { a } 10\end{array}$ & $\begin{array}{l}\text { Estefanía Unzu } \\
\text { (@verdeliss) }\end{array}$ & $\begin{array}{l}\text { Complem } \\
\text { ento } \\
\text { alimentici } \\
\text { o } \\
\text { Femibion }\end{array}$ & Sí (\#Ad) & Sí & Sí & Sí & $\begin{array}{l}1,2 \text { millones/ } \\
61.446 / \\
5,12 \%\end{array}$ \\
\hline $\begin{array}{l}\text { Figur } \\
\text { a } 11\end{array}$ & $\begin{array}{l}\text { Adara Molinero } \\
\text { (@adara_molin } \\
\text { ero) }\end{array}$ & $\begin{array}{l}\text { Té con } \\
\text { estimulant } \\
\text { es } \\
\text { Fitvia }\end{array}$ & Sí & Sí & No & Sí & $\begin{array}{l}858 \mathrm{mil} / \\
15.584 / \\
1,81 \%\end{array}$ \\
\hline $\begin{array}{l}\text { Figur } \\
\text { a } 12\end{array}$ & $\begin{array}{l}\text { Rocío Camacho } \\
\text { (@rocioccamac } \\
\text { ho) }\end{array}$ & $\begin{array}{l}\text { Té con } \\
\text { estimulant } \\
\text { es } \\
\text { Fitvia }\end{array}$ & Sí & Sí & No & Sí & $\begin{array}{l}607 \mathrm{mil} / \\
12.208 / \\
2,01 \%\end{array}$ \\
\hline Figur & Laura & Informaci & No & - & - & - & $887 \mathrm{mil} / 3$ \\
\hline
\end{tabular}

${ }^{3}$ Es una publicación en los stories de Instagram, por lo que esta publicación no tiene likes dada su naturaleza.

${ }^{4}$ Se trata de un libro, por lo que la marca es el propio título del libro. Además, se menciona el perfil personal y profesional de la coautora, publicitando dichos perfiles simultáneamente. 


\begin{tabular}{|l|l|l|l|l|l|l|l|}
\hline a 13 & $\begin{array}{l}\text { Matamoros } \\
\text { (@_Imflores })\end{array}$ & $\begin{array}{l}\text { ón sobre } \\
\text { el COVID- } \\
19\end{array}$ & & & & & \\
\hline
\end{tabular}

* Nota 1: El engagement ha sido calculado con la fórmula aportada por Núñez (s.f.), dividiendo el número de likes entre el número de seguidores y multiplicándolo por 100.

* Nota 2: el número de seguidores se consultó en mayo de 2020.

Fuente: elaboración propia, (2020)

Cabe destacar que el BOE (2002) señala que "las comunicaciones comerciales realizadas por vía electrónica deberán ser claramente identificables como tales, y la persona física o jurídica en nombre de la cual se realizan también deberá ser claramente identificable" (p. 16). En cinco de las once publicaciones que contienen publicidad explícita sobre salud no se señala ${ }^{5}$ en ningún momento la naturaleza publicitaria del mensaje, desoyendo las normas señaladas en el BOE.

\section{CONCLUSIONES}

A pesar de que el uso de Internet y las redes sociales supone muchas ventajas para el ámbito de la salud, también implica una serie de riesgos. Principalmente por la cantidad de información publicada por personas movidas por un interés económico, en lugar de por una convicción fundamentada en el avance social.

El marketing de influencia es una práctica en alza en el sector, por lo que Instagram está repleto de información relacionada con medicamentos, productos saludables, o referencias a enfermedades y patologías. Sin embargo, los prescriptores que, o bien se dedican profesionalmente a la creación de contenido, o bien son celebridades o personas influyentes de la televisión, cuentan con mayor reconocimiento y número de seguidores que aquellos profesionales sanitarios con formación en materia de salud, tal y como se puede comprobar en la Tabla 1.

Consecuentemente aquellos influencers que entre sus contenidos difunden información comercial pueden lograr una alta penetración en los usuarios a partir de contenidos de bajo rigor científico. La realidad es que estas publicaciones, a pesar de ser contenido comercial, consiguen grandes datos de engagement, siendo solo en dos de once publicaciones donde no se ha conseguido el engagement ideal. Según De Lima (2019), el engagement debería superar el $2 \%$ para considerar que la publicación ha sido afín y ha conseguido una buena aceptación entre la comunidad del influencer.

Otro aspecto que considerar sobre estos posts promocionados es que señalar lo habitual que resulta que el influencer mencione a la marca, así como la inclusión de fotografías del propio producto y, con menor frecuencia, hashtags propios de la campaña. Con estos elementos, podemos afirmar que a pesar de que se hace publicidad explícita, en numerosas ocasiones no se identifica como tal, algo obligatorio en España.

5 Habitualmente, las publicaciones con contenido patrocinado por alguna marca se identifican con el \#ad. En la Tabla 2 se recoge si las publicaciones cuentan o no con este identificador u otro equivalente. 
Como hemos podido comprobar, este tipo de publicaciones son muy aceptadas entre la población. Por lo que las personas confían en estas recomendaciones, incluso cuando tratan sobre productos farmacológicos que necesitan la prescripción o valoración por parte de un facultativo o farmacéutico. La razón de este suceso, como ya han analizado Pilgrim y Bohnet-Joschko (2019), tiene que ver con el efecto de cercanía que generan estos influencers en sus seguidores al llegar, en los casos más extremos, a un nivel de identificación personal que hace percibir a los influencers como amigos a los que pedir consejo.

Así mismo, cabe destacar, que los influencers profesionales de la salud que se han analizado tienen muchos menos seguidores que el resto de los perfiles. Esto podría significar que, en consecuencia, son más las personas que reciben información por parte de quienes difunden información comercial, que por parte de aquellos profesionales del sector que comparten información veraz en redes sociales. El resultado de eso es la influencia en los usuarios de un contenido caracterizado por su escaso rigor científico y no de uno veraz, educativo y de calidad.

Se manifiesta, por tanto, la necesidad de que las instituciones generen, y den a conocer, nuevas estrategias de e-salud que garanticen una vida saludable, promuevan el bienestar y resuelvan las cuestiones planteadas en esta revisión. Pues, a pesar de que los organismos oficiales han tomado una actitud más activa en cuanto a las estrategias de educación sanitaria, sobre todo a raíz de la pandemia del Covid-19, se plantea el requerimiento de iniciativas que combatan la adhesión de los ciudadanos a figuras influyentes que no juegan a favor de la alfabetización en salud.

\section{REFERENCIAS}

Abt-Sacks, A., Pablo Hernando, S., Serrano Aguilar, P., Fernández Vega, E. y Martín Fernández, R. (2013). Necesidades de información y uso de Internet en pacientes con cáncer de mama en España. Gaceta Sanitaria, 27(3), 241-247. https://doi.org/10.1016/i.gaceta.2012.06.014

Aguado-Guadalupe, G. y Bernaola-Serrano, I. (2020). Verificación en la infodemia de la Covid-19. El caso Newtral. Revista Latina de Comunicación Social, 78, 289-308. https://doi.org/10.4185/RLCS-2020-1478

Aguado, G. y García, A. (2009). Del Word-of-mouth al Marketing viral: aspectos claves de la comunicación a través de redes sociales. Comunicación y Hombre, 5. https://comunicacionyhombre.com/article/del-word-of-mouth-al-marketing-viralaspectos-claves-la-comunicacion-traves-redes-sociales/

Álvarez. A. (2014). "Publicidad y salud": un manual práctico para conocer los cambios. Revista de Comunicación y salud, 4(1), 109-114.

https://doi.org/10.35669/revistadecomunicacionysalud.2014.4(1).109-114 
Arantón Areosa L. (2014). Prescribir Links y Apps para empoderar a los pacientes. Enfermería Dermatológica, 8(22), 44-49. http://www.anedidic.com/descargas/dermared/22/prescribir-links-y-apps.pdf

Ávila-Tomás, J. F., Olano-Espinosa, E., Minué-Lorenzo, C., Martínez-Suberbiola, F. J., Matilla-Pardo, B. y Serrano-Serrano, E. (2019). Nuevas herramientas de comunicación digitales entre profesionales de la salud y pacientes. A propósito del proyecto Dejal@Bot. Revista de Comunicación y Salud, 9(2), 55-70. https://doi.org/10.35669/revistadecomunicacionysalud.2019.9(2).55-70

Baudrillart, M. A., Pelletier, K., Zimmerli, V. y Badillo, P. Y. (2018). Identification et typologie des e-influenceurs: analyse des flux d'information sur Twitter dans le domaine de la prévention en santé. Colloque international - Réseaux sociaux, traces numériques et communication électronique, 685-696. https://archiveouverte.unige.ch/unige:105814

BOE. (2002). Ley 34/2020, de 11 de julio, de servicios de la sociedad de la información y de comercio electrónico. https://www.boe.es/eli/es///2002/07/11/34/con

Byrne, E., Kearney, J. y MacEvilly, C. (2017). The role of influencer marketing and social influencers in public health. Proceedings of the Nutrition Society, 76(OCE3), E103. https://doi.org/10.1017/S0029665117001768

Campos, F., Gago, M. y López, A. M. (2010). Desarrollo de una nueva herramienta de análisis y gestión de la conversación de los medios sociales. Virtualis. https://www.revistavirtualis.mx/index.php/virtualis/article/view/26/15

Castelló, A. (2010, 19 de julio). Crossumer, prosumer, fansumer y persumer. Observatorio Comunicación en Cambio. https://comunicacionencambio.com/crossumer-prosumerfansumer-y-persumer/

Castelló-Martínez, A. y Del Pino Romero, C. (2015). La comunicación publicitaria con influencers. Redmarka: Revista Académica de Marketing Aplicado, 14, 21-50. http://hdl.handle.net/2183/22922

Castells, M. (2003). La dimensión cultural de internet. Andalucía Educativa, 36, 7-10. https://n9.cl/gvgy5

Castells, M. (2009) Comunicación y poder. Alianza Editorial.

Cernadas, A., Bouzas-Lorenzo, R., Mesa del Olmo, A. y Barral, B. (2019). Opinión de los facultativos y usuarios sobre avances de la e-salud en atención primaria. Atención Primaria. https://doi.org/10.1016/..aprim.2019.05.008

Cgcof. (2020). Influencers prescriptores de medicamentos. [Argumentario]. https://n9.cl/cofteruel 
Cgcof. (2020, 3 de febrero). Una campaña del Consejo General de Farmaceúticos y \#SaludsinBulos alerta sobre los consejos de influencers sobre medicamentos. [Nota de prensa]. https://n9.cl/portalfarma

Coates, A. E., Hardman, C. A., Halford, J. C. G., Christiansen, P. y Boyland, E. J. (2019). Food and beverage cues featured in youtube videos of social media influencers popular with children: an exploratory study. Frontiers in Psychology, 10, 21-42. https://doi.org/10.3389/fpsyg.2019.02142

Comscore (2020). Coronavirus pandemic and online behavioural shifts. Comscore. https://n9.cl/wu51

De Lima, Y. (2019). ¿Cómo saber si tu engagement es bueno o malo? Lima Marketing Digital. https://www.lima-marketingdigital.com/engagement-en-instagram/

Deprez, F. (2016). La twittliste du secteur pharmaceutique. Netsources, 123, 14-15.

Descriptores en Ciencias de la Salud (DeCS). Telemedicina. https://n9.cl/rkri

Díaz de León, C. (2019). Salud electrónica (e-Salud): un marco conceptual de implementación en servicios de salud. Gaceta Médica de México, 155(2), 176-183. https://www.medigraphic.com/cgi-bin/new/resumenl.cgi?IDARTICULO=86526

Dueñas, P. P. M., Domínguez, C. S. y Coronil, A. G. (2020). El influencer marketing y el proceso de compra de los estudiantes universitarios. En Liberal Ormaechea, S. y Mañas Viniegra, L. (coord.), Las redes sociales como herramienta de comunicación persuasiva, (pp.91-106). Madrid: McGraw-Hill Interamericana de España.

EUROSTAT. (2020). Individuals using the internet for seeking health-related information. Eurostat.

https://ec.europa.eu/eurostat/databrowser/view/tin00101/default/table?lang=en

Eysenbach, G. (2009). Infodemiology and infoveillance: framework for an emerging set of public health informatics methods to analyze search, communication and publication behavior on the Internet. Journal of Medical Internet Research, 11(1). https://doi.org/10.2196/imir.1157

El País. (2019, 16 de mayo). Desconfía de los influencers de salud: solo uno de cada nueve da buenos consejos. El País. https://elpais.com/elpais/2019/05/13/buenavida/1557758806 589528.html

Falcón, M. y Luna, A. (2012). Alfabetización en salud: concepto y dimensiones. Proyecto europeo de alfabetización en salud. Revista Comunicación y Salud. 2(2), 91-98. http://www.revistadecomunicacionysalud.es/index.php/rcys/article/view/130 
Farré, J., Gonzalo, J. L., Lores, M., Lozano, N. y Prades, J. (2012). Comunicación de riesgos y seguridad alimentaria en la era 2.0. El Profesional de la Información. 21(4), 381-384. https://doi.org/10.3145/epi.2012.jul.08

Fernández Salazar, S. y Ramos Morcillo, A. J. (2013). Prescripción de links y de aplicaciones móviles fiables y seguras, ¿estamos preparados para este nuevo reto. Evidentia, 10(42). http://www.index-f.com/evidentia/n42/ev4200.php

Ferret, C. (2019, julio). Combinar estrategia de salud con influencers, una receta de éxito. PMFarma. http://www.pmfarma.es/articulos/2666-combinar-estrategia-de-salud-coninfluencers-una-receta-de-exito.html

García Núñez, R. y García Huerta, D. G. (2018). Una aproximación a la cultura de Internet y participativa. Sincronía, 74, 452-466. https://www.redalyc.org/jatsRepo/5138/513855742024/html/index.html

García, M. (2020, 15 de febrero). Por qué algunos influencers son una amenaza para la salud. El Mundo. https://n9.cl/elmundo

Gil-Torres, A., Martín-Quevedo, J., Gómez-García, S. y San José-De la Rosa, C. (2020). El coronavirus en el ecosistema de los dispositivos móviles: creadores, discursos y recepción. Revista Latina de Comunicación Social, 78, 329-358. https://www.doi.org/10.4185/RLCS-2020-1480

González, G. y Molina, G. (2003). La Informática Médica y los Sistemas de Información. http://medicinadefamiliares.cl/Trabajos/infosiscgs.pdf

Hartzband, P. y Groopman, J. (2010). Untangling the Web-patients, doctors, and the Internet. New England Journal of Medicine, 362(12), 1063-1066. https://www.nejm.org/doi/full/10.1056/NEJMp0911938

Hawn, C. (2009). Take two aspirin and tweet me in the morning: how Twitter, Facebook, and other social media are reshaping health care. Health affairs, 28(2), 361-368. https://doi.org/10.1377/hlthaff.28.2.361

Henwood, F., Wyatt, S., Hart, A. y Smith, J. (2003). 'Ignorance is bliss sometimes': constraints on the emergence of the 'informed patient' in the changing landscapes of health information. Sociology of Health \& IIIness, 25(6), 589-607. https://doi.org/10.1111/1467-9566.00360

IAB Spain. (2019). Libro blanco de marketing de influencers. https://iabspain.es/estudio/libro-blanco-de-marketing-de-influencers/

IAB Spain. (2020). Estudio de Redes Sociales 2020. https://iabspain.es/estudio/estudioredes-sociales-2020/ 
iSanidad (2020). Guillermo Martín (Farmacia Enfurecida): "El principal problema con los influencers no está en YouTube sino en Instagram". iSanidad. https://n9.cl/isanidad

Isorna, M., de la Cruz, E. y Villanueva, V. J. (2020). La violencia tabáquica: papel de los medios audiovisuales, influencers y las think tanks. Revista Española de Drogodependencias, 45(1), 101-110. https://www.aesed.com/upload/files/v45n18 misorna.pdf

Jaubert, E. y Dolbeau-Bandin, C. (2020). Infox et coronavirus Covid-19: une relative contagiosité? https://hal.archives-ouvertes.fr/hal-02542132/

Jiménez-Pernett, J., García-Gutiérrez, J. F., Martín-Jiménez, J. L. y Bermúdez-Tamayo, C. (2007). Tendencias en el uso de Internet como fuente de información sobre salud. UOC Papers: Revista sobre la sociedad del conocimiento, 4, 10. https://www.redalyc.org/pdf/790/Resumenes/Resumen 79000411 1.pdf

Khan, R. E. (2020). Viral News on the Coronavirus: Does it Contribute to Health Communication? Trípodos, 47(1), 49-66. http://www.tripodos.com/index.php/Facultat Comunicacio Blanquerna/article/view/80 $\underline{3}$

Larrain Sundt, M. E., y Arrieta Cucurella, M. (2010). Influjo de las imágenes femeninas presentadas por los medios de comunicación sobre el desarrollo adolescente. Mercurio Peruano, 523, 69-80. https://dialnet.unirioja.es/servlet/articulo?codigo=3691184

Leis, A., Mayer, M. A., Torres, J. Rodríguez-González, A., Suelves, J.M. y Armayones, M. (2013). Grupos sobre alimentación saludable en Facebook: características y contenidos. Gaceta Sanitaria, 27(4), 355-357. https://doi.org/10.1016/i.gaceta.2012.12.010

Lilly (2020, 12 de febrero). Chicote afirma que "en San Valentín, más que nunca, es importante cuidar del corazón, sobre todo si tienes diabetes". [Comunicado de prensa]. https://n9.cl/fojb

Linde, P. (2020, 9 de enero). Influencers nocivas para la salud. El País. https://elpais.com/sociedad/2020/01/08/actualidad/1578509328 514133.html

Martín Fombellida, A. B., Alonso Sardón, M., Iglesias de Sena, H., Sáez Lorenzo, M. y Mirón Canelo, J. A. (2014). Información sobre medicamentos y automedicación en las redes sociales. Revista Cubana de Información en Ciencias de la Salud, 25(2), 145156.

http://scielo.sld.cu/scielo.php?script=sci arttext\&pid=S2307-

$\underline{21132014000200002}$

Martínez, C. A. y Sosa, M. A. (2016). Aportaciones y diferencias entre comunicación en salud, comunicación para el desarrollo y para el cambio social. Revista de 
Comunicación y Salud, 6(1),71-82. https://doi.org/10.35669/revistadecomunicacionysalud.2016.6(1).71-82

McNab, C. (2009). What social media offers to health professionals and citizens. Bulletin of the World Health Organization, 87, 566. https://www.who.int/bulletin/volumes/87/8/09-066712/en/

Medlineplus (2020, 21 de enero). Cannabidiol (CBD). MedlinePlus. https://medlineplus.gov/spanish/druginfo/natural/1439.html

Moreira, J. y Camara, S. (2012). Saúde Web 2.0 e comunicação em saúde: a participação em comunidades virtuais em Portugal. Revista de Comunicación y Salud, 2(2), 47-62. http://www.revistadecomunicacionysalud.es/index.php/rcys/article/view/127

Monteagudo, J. L. (2001). El marco de desarrollo de la e-Salud en España. https://repisalud.isciii.es/handle/20.500.12105/4956

Negrete, B. (2019, 19 de diciembre). Petición de Sanidad para sacar a los "influencers prescriptores" de YouTube. Redacción Médica. https://n9.cl/1rp1

Núñez, V. (s.f.). Fórmula para calcular engagement en redes sociales y CTR. Vilma Núñez Blog. https://vilmanunez.com/formula-engagement-redes-sociales-ctr/

Pilgrim, K. y Bohnet-Joschko, S. (2019). Selling health and happiness how influencers communicate on Instagram about dieting and exercise: Mixed methods research. BMC Public Health, 19(1), 1054. https://doi.org/10.1186/s12889-019-7387-8

Rodríguez, A. (2019). Evolución de la atención telemática por enfermería en una unidad monográfica de enfermedad inflamatoria intestinal [Tesis Doctoral, Universidad $\begin{array}{llll}\text { Complutense de Madrid]. } & \text { Repositorio }\end{array}$ https://eprints.ucm.es/51740/1/T40991.PDF

Rojas Piñango, A. J., de la Cruz Sánchez, E. E. y Ramírez Hernández, B. E. (2018). Blog en educación alimentaria y nutricional. Una herramienta de comunicación y educación para promover en salud integral. Revista de Comunicación y Salud, 8, 111-126. https://doi.org/10.35669/revistadecomunicacionysalud.2018.8(1).111-126

Redacción Médica (2019, 12 de noviembre). Triple alianza contra los "influencers" que recomiendan fármacos. Redacción Médica. https://www.redaccionmedica.com/virico/noticias/-indignacion-video-instagram-martacarriedo-recomendacion-influencer-antibiotico-receta--2387

Salud sin Bulos y Doctoralia (2019). II Estudio sobre Bulos en Salud. Encuesta a profesionales de la salud en España. Salud sin bulos. https://saludsinbulos.com/wpcontent/uploads/2019/11/es-II-estudio-bulos-salud.pdf 
Santamaría-Ochoa, C. D., Catalán-Matamoros, D. y Merced-Macías de León, J. (2016). Utilización de las redes sociales sobre temas de salud en población universitaria de México. Revista Española de Comunicación en Salud, 7(1), 15-28. https://erevistas.uc3m.es/index.php/RECS/article/view/3165

Sanz-Lorente, M. y Castejón Bolea, R. (2019). Redes sociales: Recursos interactivos y la información sobre salud. Hospital a Domicilio, 3(4), 269-277. http://dx.doi.org/10.22585/hospdomic.v3i4.84

Sanz-Valero, J., Castiel, L. D., Wanden-Berghe, C. y Juan Quilis, V. (2006). Internet y la búsqueda de información en salud pública: desde la relevancia hacia la «revelancia». Gaceta Sanitaria, 20, 159-160. https://gacetasanitaria.org/es-pdf$\underline{\text { S0213911106714753 }}$

Seva Ruiz, M. y Casadó Marín, L. C. (2015). La construcción de la identidad e imagen corporal en la adolescencia a través de los medios de comunicación social: estrategias para el desarrollo de un modelo de prevención. Enfermería integral: Revista científica del Colegio Oficial de Enfermería de Valencia, 108, 68-73. https://www.enfervalencia.org/ei/108/ENF-INTEG-108.pdf

Solé, F. J. (2003). Internet en medicina ¿una ayuda, un problema, una causa de errores...? Comunicación especial. Actas Urológicas Españolas, 27(3), 180-184. http://scielo.isciii.es/scielo.php?script=sci arttext\&pid=S0210-48062003000300002

Tardón, L. (2015, 27 de mayo). Dentistas denuncian la venta ilegal de un blanqueante dental.

El Mundo. https://www.elmundo.es/salud/2015/05/27/5565d45446163f5e388b4589.html

Villaescusa Martínez, V. y Sáez Villar, L. (2013). Búsqueda de información sobre salud a través de Internet. Enfermería Global, 12(3), 197-205. https://doi.org/10.6018/eglobal.12.3.166301

Wilson, P. y Risk, A. (2002). How to find the good and avoid the bad or ugly: a short guide to tools for rating quality of health information on the internet Commentary: On the way to quality. Bmj, 324(7337), 598-602. https://doi.org/10.1136/bmj.324.7337.598

\section{AUTORES}

\section{Ainhoa García-Rivero}

Graduada en Publicidad y Relaciones Públicas por la Universidad Complutense de Madrid, especialista en Comunicación de las Organizaciones y doctoranda en el programa de Doctorado de Comunicación Audiovisual y Publicidad y Relaciones Públicas de esta misma universidad. Ejecutiva de Planificación en Atresmedia Publicidad. Su principal línea de investigación reside en la comunicación en redes sociales y la comunicación de productos infantiles. 
Orcid ID: https://orcid.org/0000-0003-4879-9950

Google Scholar: https://scholar.google.com/citations?user=ZiTINFUAAAAJ

\section{Emma G. Carbonell-Curralo}

Graduada en Periodismo por la Universidad de Valladolid y especializada en Comunicación de las Organizaciones por la Universidad Complutense de Madrid. Con experiencia en comunicación del ámbito cultural y sanitario.

Orcid ID: https://orcid.org/0000-0001-8879-6581

Google Scholar: https://scholar.google.com/citations?hl=es\&user=jBKOgDMAAAAJ

\section{Ana Magán-Álvarez}

Graduada en Comunicación Audiovisual y Administración y Dirección de Empresas por la Universidad Rey Juan Carlos de Madrid. Con experiencia en áreas de marketing y desarrollo de negocio en el sector del entretenimiento.

Orcid ID: https://orcid.org/0000-0003-0099-8037

\section{Rafael Barberá-González}

Acreditado a la figura de Profesor Contratado Doctor por la ANECA. Doctor en Periodismo por la Universidad San Pablo-CEU, licenciado en Periodismo por esta Universidad y licenciado en Derecho por la UCM. Profesor en la Facultad de Ciencias de la Información de la UCM, en la Facultad de Comunicación de la UFV, en IE University y en The College for International Studies. Sus líneas de investigación se centran en la comunicación política y la comunicación de crisis. Ha publicado varios artículos científicos sobre estas materias.

Orcid ID: https://orcid.org/0000-0003-0099-8037 
Marketing de influencia: educación sanitaria online

\section{ANEXO}

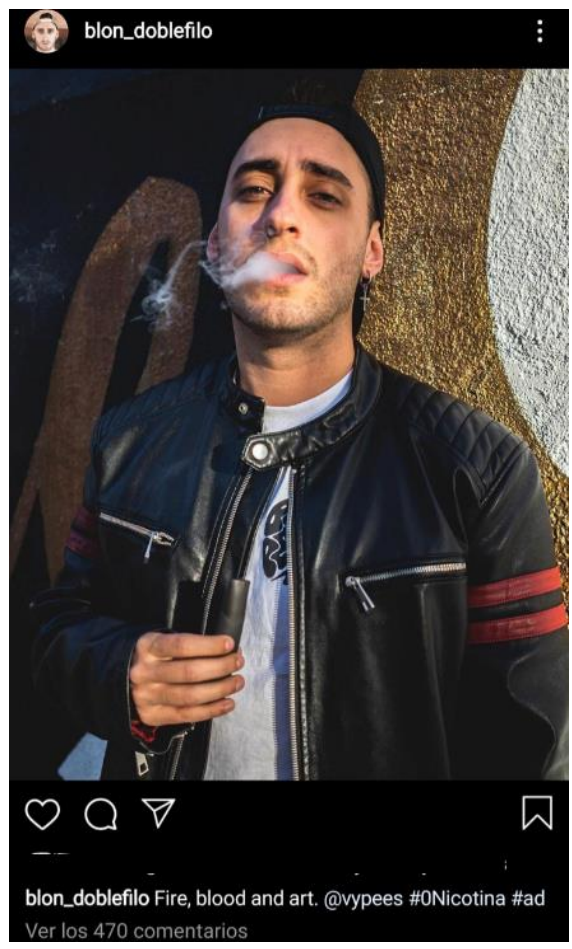

Figura 1. Screenshot de colaboración con marca de vapper Fuente: Instagram de Pablo Pérez "Blon" @blon_doblefilo 
Marketing de influencia: educación sanitaria online

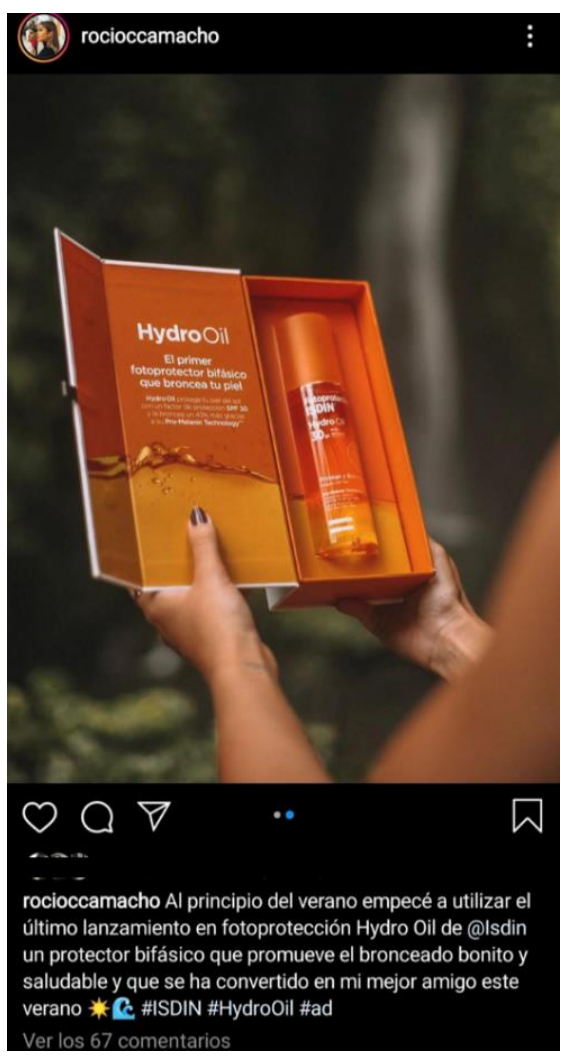

Figura 2. Screenshot de colaboración con producto de fotoprotección. Fuente: Instagram de Rocio Camacho@rocioccamacho 
Marketing de influencia: educación sanitaria online

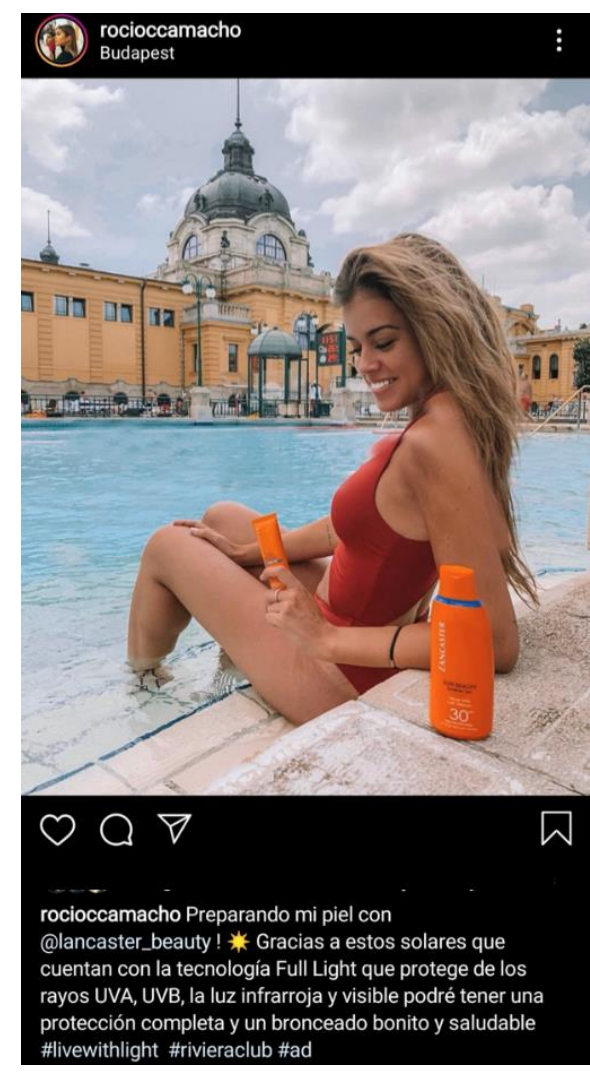

Figura 3. Screenshot de colaboración con producto de fotoprotección.

Fuente: Instagram de Rocio Camacho@rocioccamacho 
Marketing de influencia: educación sanitaria online

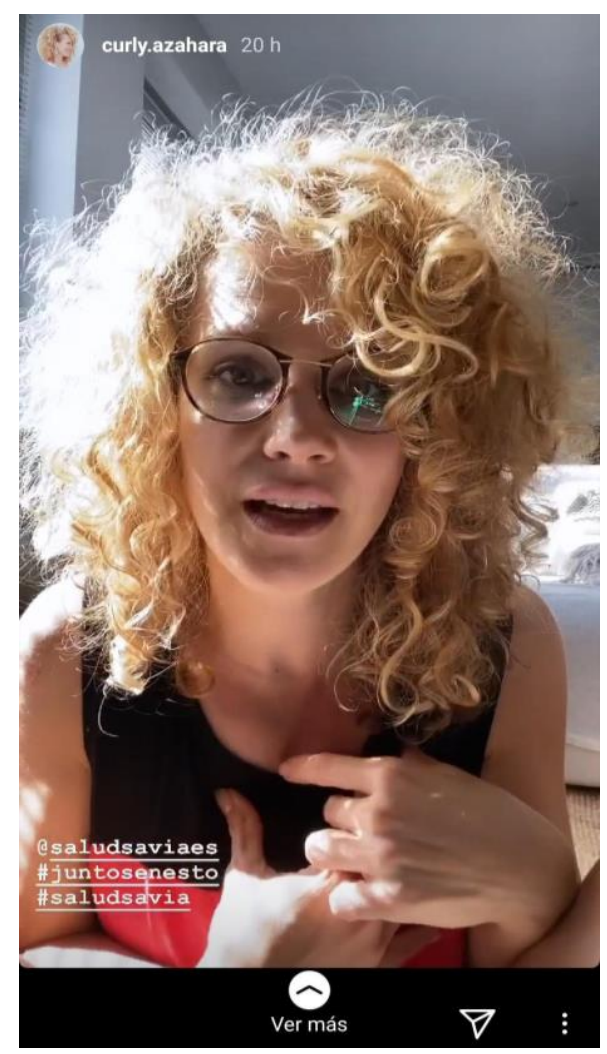

Fuente: Instagram Stories de Azahara Luque @curly.azahara Figura 4. Screenshot de publicidad de aplicación móvil.

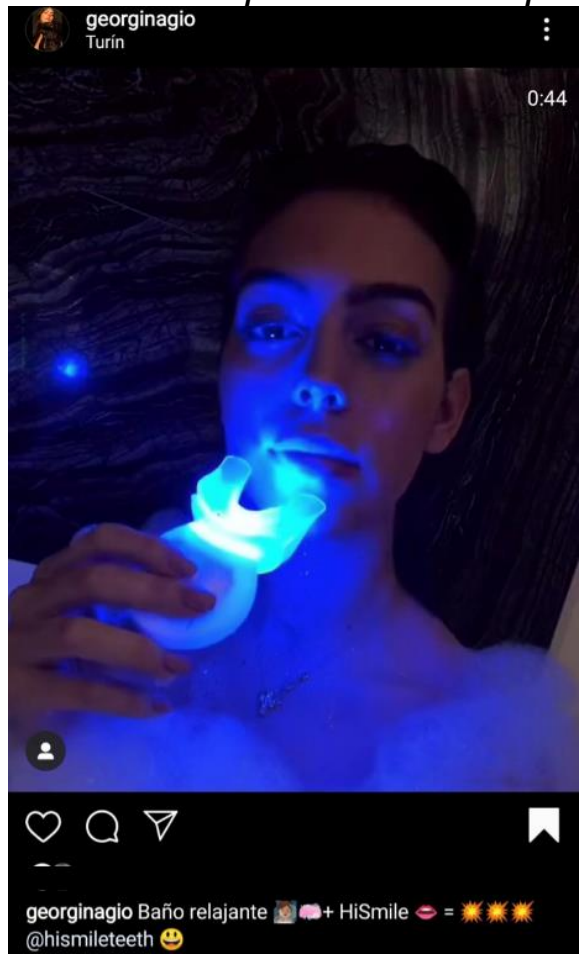

Figuras 5. Screenshot de publicidad de blanqueadores dentales. 
Marketing de influencia: educación sanitaria online

Fuente: Instagram de Georgina Rodríguez @georginagio

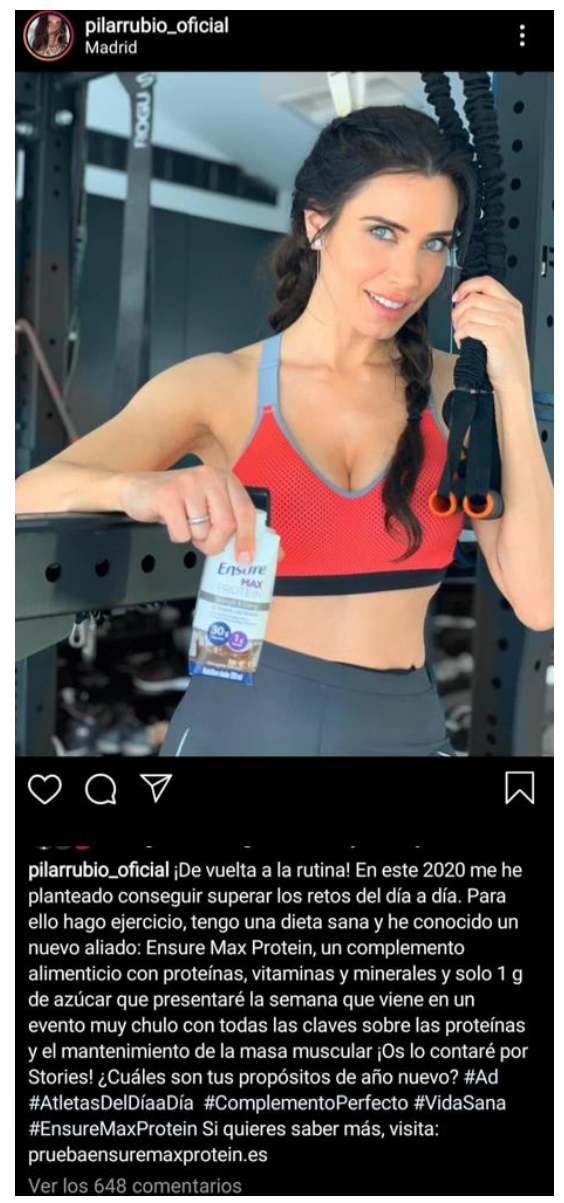

Figuras 6. Screenshot de colaboración con marca de complemento alimenticio.

Fuente: Instagram de Pilar Rubio @pilarrubio_oficial 
Marketing de influencia: educación sanitaria online

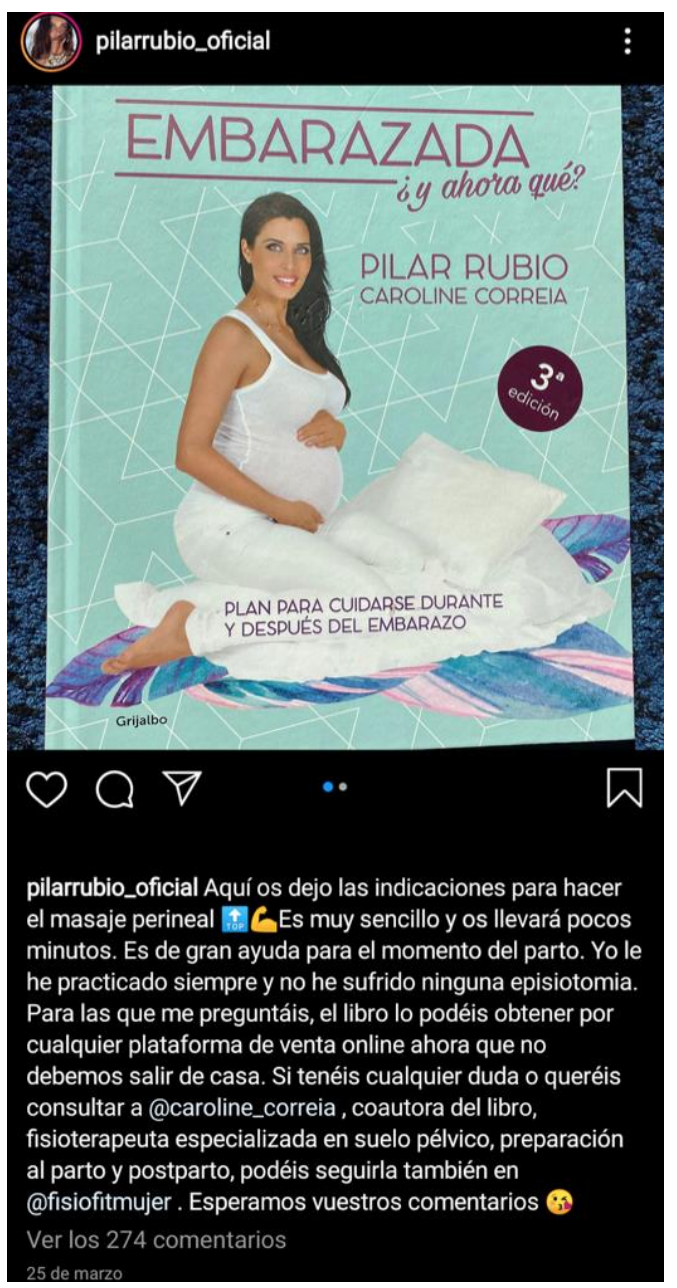

Figuras 7. Screenshot de publicidad de libro sobre maternidad. Fuente: Instagram de PilarRubio @pilarrubio_oficial 
Marketing de influencia: educación sanitaria online

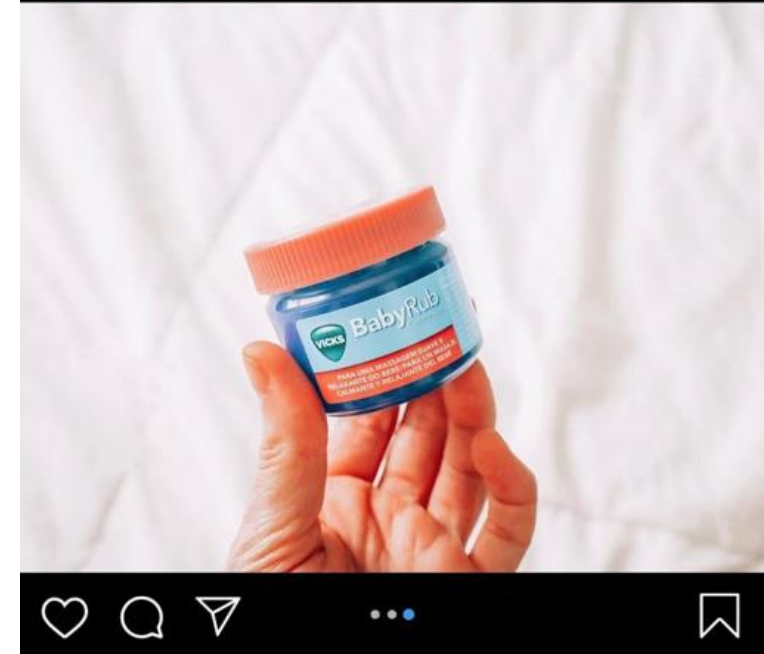

verdeliss $\mathrm{MA} \cdot \mathrm{RA} \cdot \mathrm{VI} \cdot \mathrm{LLA} \cdot \mathrm{DA}$ Fijaos que había escuchado veces recomendaciones de BabyRub (a todos los "vecinos de", "hijos de", "sobrino de" les va genial jeje, cuánto hace él boca-a-boca) pero aún no lo habíamos probado.

Total, nos contactó la marca...y coincidiendo que Miren con estas fechas de resfriados está más quejosa que nunca para coger el sueño, nos animamos a introducirlo en la rutina de noche.

¡Bendito el momento en que comenzamos con estos masajes! ¡Se queda súper reconfortada y es tan tierno ese ratito de caricias...tan nuestro, tan especial! Nuestros minutitos de mimos en que entra en modo relax y lo agradece para dormir.

Os cuento: Es apto para bebés a partir de 6 meses de edad y se aplica una vez cada noche, en tripita y pecho, con movimientos circulares. Tranquilidad total para usarlo por el tiempo que deseéis...ya que no es un medicamento, sinó un bálsamo (mágico, pero un ungüento jeje) con efecto aromático y su fórmula lleva:.

-Lavanda y Romero: utilizadas tradicionalmente por su acción balsámica y calmante -Aloe Vera: Potente poder hidratante.

Espero que os sea de ayuda nuestra reseña, a ver si recuerdo subiros stories, porque vais a morir de amor con Miren $\odot$ ¿Vosotros ya conocíais BabyRub? Contadme!!!

\#MomentosVicksBaby

\#Verdeliss \#Miren \#9Meses [ad]

Ver los 931 comentarios

Figura 8. Screenshot de recomendación de BabyRub Fuente: Instagram de Estefanía Unzu @verdeliss 


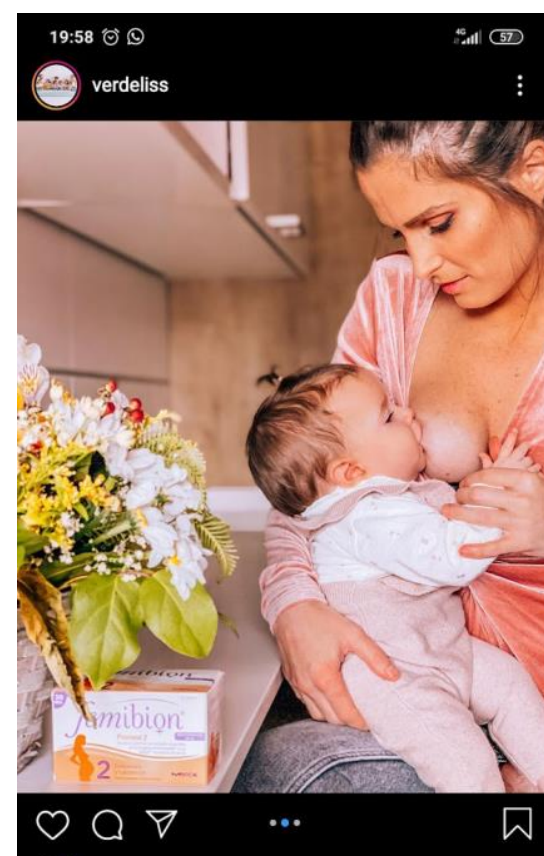

( 3 Les gusta a paaaaattttly y otras personas

verdeliss iiiEmocionada de contaros que me han elegido embajadora de Femibion!!! ¿Por qué tan feliz de estos suplementos en concreto? Porque marcan la diferencia: son polivitamínicos con un tipo de ácido fólico llamado Metafolin( - Esta es una forma activa de folato que no necesita ser transformado, pudiendo así ser utilizado

directamente por el cuerpo de la madre. Sabiendo además lo siguiente

$\checkmark$ La recomendación de suplementar con ácido fólico 1 mes antes del embarazo y hasta 3 después para cubrir los $400 \mathrm{mgc}$ y así ayudar a un correcto desarrollo del tubo neural del bebé.

X Los estudios determinan que un $50 \%$ de las mujeres no metabolizan correctamente el ácido fólico por una

mutación en una enzima que hace pueda perder parte de actividad.

Más que nunca motivos para apostar por Femibion!!! jeje.

Yo además, dando el pecho, tomo Femibion 2... ahora por el tema del yodo, ya que ayuda a la formación normal de

hormonas tiroideas y a la función de la tiroides, importante

en la lactancia. Apunte: Siempre he apostado por

polivitamínicos en estas etapas jeje. Lo fundamental, la

dieta, pero a mí, personalmente, que sean tan completos,

me aporta tranquilidad y eso me vale oro $\Theta$ (es lo que

tiene ser un poco agonías jeje).

Ya que menciono Femibion 2, que está indicado para el embarazo/lactancia, os cuento que Femibion 1 incluye pequeñitos cambios en la composición que lo hacen

recomendado para la pre-concepción (recordad que el

ácido fólico hay que comenzarlo 1 mes antes de la

búsqueda) hasta la semana 13 de embarazo.

Espero que os haya sido útil esta info y considerad que $\mathrm{mi}$ postura es siempre desde mis vivencias como madre

1

Tenéis toda la información disponible en

https://www.femibion.com/es_ES/productos/femibion -pronatal-1.html. Femibion son complementos alimenticios, no sustituyen una dieta sana y equilibrada ni un estilo de vida saludable, no se debe superar la dosis diaria recomendada y hay que mantenerlos fuera del

alcance de los niños más pequeños.

\#Verdeliss [ad]

Ver los 235 comentarios

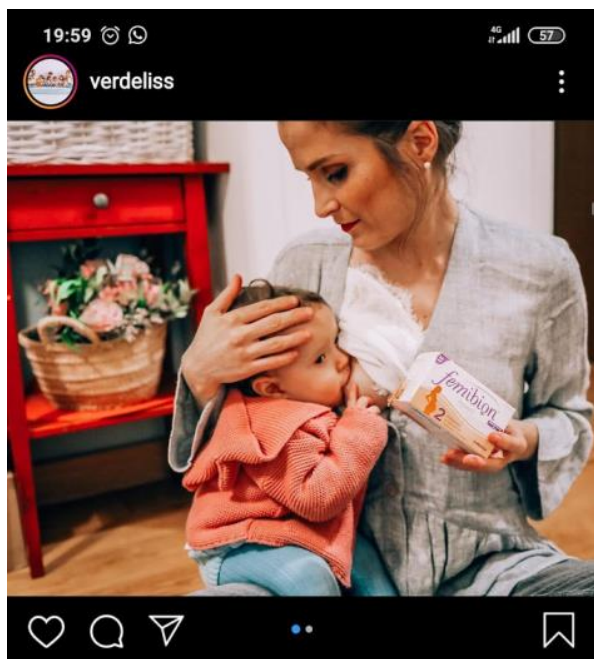

(9) Les gusta a raquetiya y otras personas

verdeliss Me preguntáis mucho que cuando dejaremos la lactancia y en verdad, no tengo respuesta 9 Bien porque Miren deje de mostrar interés (cada vez la veo comiendo más sólidos y más "desapegada" jugando y explorando), bien porque me apetezca a mi: tengo claro que lo mismo que supe escucharme cuando deseé luchar contra viento y marea para instaurar la lactancia, espero saber escuchar mi voluntad cuando sienta es el momento de destetar $\mathbf{C}$

Mientras tanto, se sigue repitiendo esta escena jeje, un año ya y muriendo de amor!!!

Os enseño la caja de @femibion_es porque os lo recomiendo como polivitamínico durante la lactancia $\mathbf{\Omega}$ (por el tema del yodo, ya que ayuda a la formación normal de hormonas tiroideas y a la función de la tiroides

importantísimo!!!).

Pero ojo, también y especialmente durante el embarazo 2 ya que lleva un tipo de ácido fólico llamado Metafolin ${ }^{\circledR}$ Esta es una forma activa de folato que no necesita ser

transformado, pudiendo así ser utilizado directamente por el cuerpo de la madre.

Tengamos en cuenta además:

$\checkmark$ La recomendación de suplementar con ácido fólico 1 mes antes del embarazo y hasta 3 después para cubrir los $400 \mathrm{mgc}$ y así ayudar a un correcto desarrollo del tubo

neural del bebé.

X Los estudios determinan que un $50 \%$ de las mujeres no metabolizan correctamente el ácido fólico por una

mutación en una enzima que hace pueda perder parte de actividad.

Yo no tengo duda: @femibion_es como elección, no hay otro igual respecto a la absorción del ácido fólico $\mathrm{\partial}$. Os cuento cómo funcionan ambas opciones:

- Femibion 1: desde 1 mes antes de la concepción y durante las 12 primeras semanas de embarazo.

- Femibion 2: segundo y tercer trimestre de embarazo y periodo de lactancia.

Igualmente, tenéis toda la información disponible en https://www.femibion.com/es_ES/productos.html .

Femibion son complementos alimenticios, no sustituyen una dieta sana y equilibrada ni un estilo de vida saludable, no se debe superar la dosis diaria recomendada y hay que mantenerlos fuera del alcance de los niños más pequeños. 
Marketing de influencia: educación sanitaria online

Figuras 9 y 10. Screenshot de recomendación de Femibion Fuente: Instagram de Estefanía Unzu @verdeliss

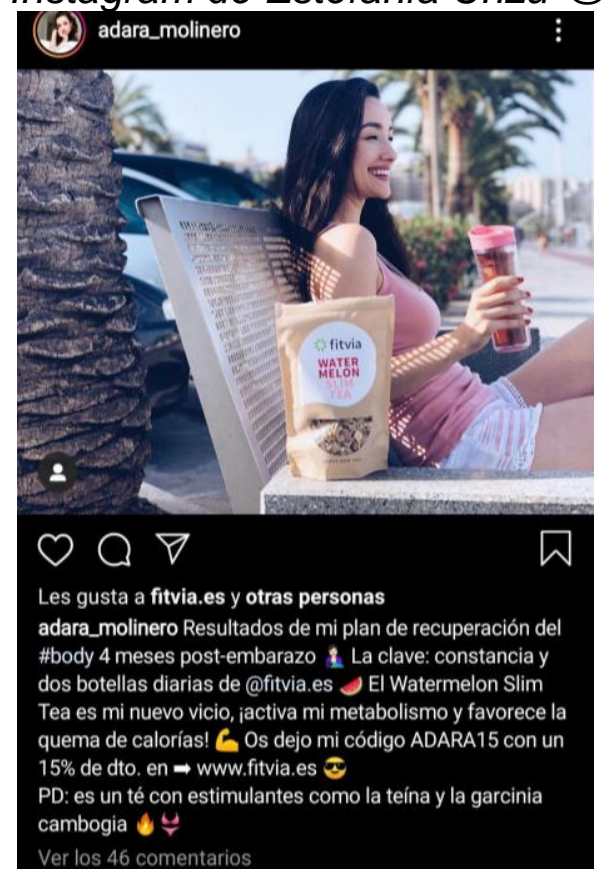

Figura 11. Screenshot de colaboración con la marca Fitvia Fuente: Instagram de Adara Molinero@adara_molinero 
Marketing de influencia: educación sanitaria online

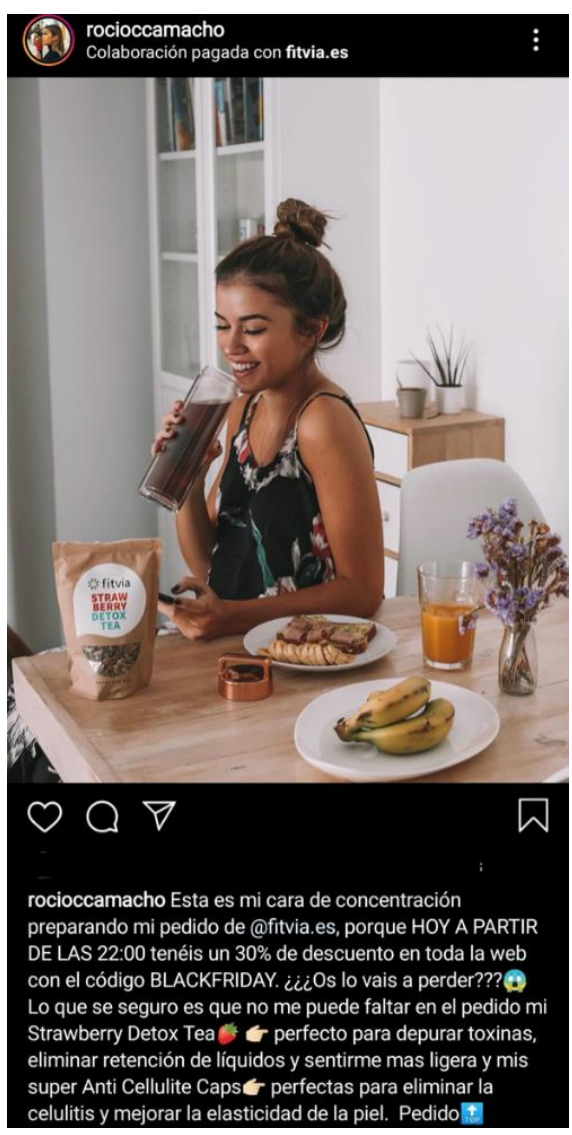

Figura 12. Screenshot de colaboración con la marca Fitvia Fuente: Instagram de Rocio Camacho@rocioccamacho 
Marketing de influencia: educación sanitaria online

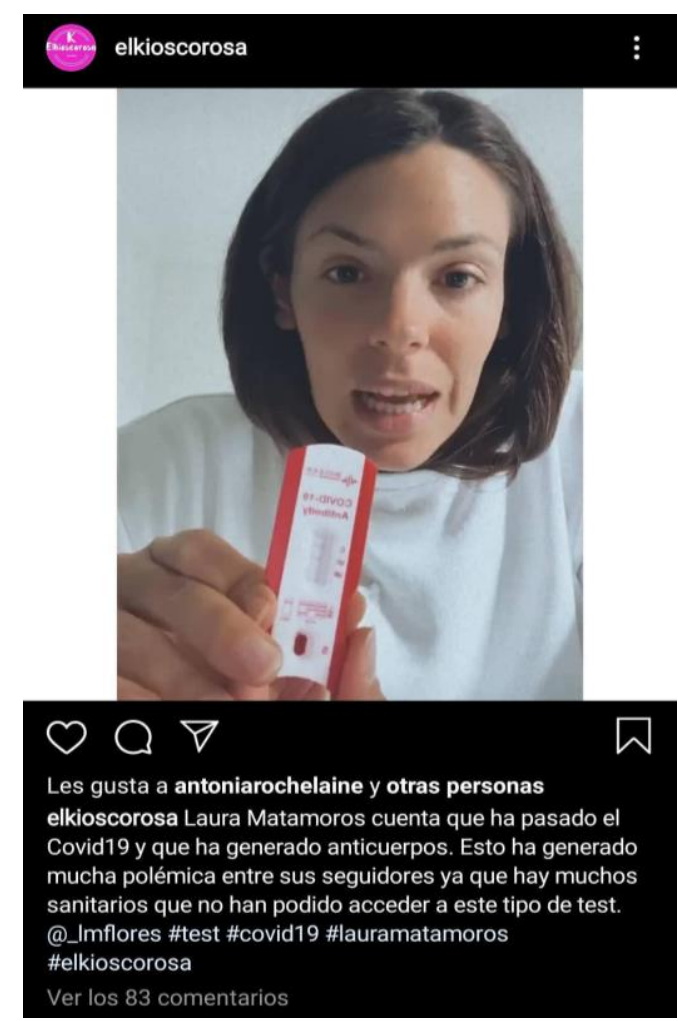

Figura 13. Screenshot de post sobre Laura Matamoros Fuente: Instagram de El Kiosko Rosa @elkioskorosa 